\title{
OPEN Thyroid hormone receptor alpha sumoylation modulates white adipose tissue stores
}

\author{
Yan-Yun Liu ${ }^{1 \bowtie}$, Jingjing Jiang ${ }^{1,2}{ }^{2}$ Sujie $\mathrm{Ke}^{1,3}$, Anna Milanesi $^{1}$, Kiyomi Abe ${ }^{1,4,5}$, \\ Gilberto Gastelum ${ }^{1}$, Jianrong $\mathrm{Li}^{1,3}$ \& Gregory A. Brent ${ }^{1 \otimes}$
}

Thyroid hormone (TH) and thyroid hormone receptor (THR) regulate stem cell proliferation and differentiation during development, as well as during tissue renewal and repair in the adult. THR undergoes posttranslational modification by small ubiquitin-like modifier (SUMO). We generated

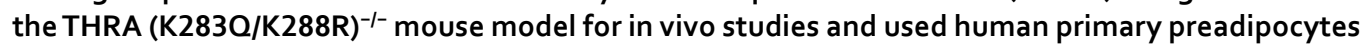
expressing the THRA sumoylation mutant (K283R/K288R) and isolated preadipocytes from mutant mice for in vitro studies. THRA mutant mice had reduced white adipose stores and reduced adipocyte cell diameter on a chow diet, compared to wild-type, and these differences were further enhanced after a high fat diet. Reduced preadipocyte proliferation in mutant mice, compared to wt, was shown after in vivo labeling of preadipocytes with EdU and in preadipocytes isolated from mice fat stores and studied in vitro. Mice with the desumoylated THRA had disruptions in cell cycle $G_{1} / S$ transition and this was associated with a reduction in the availability of cyclin D2 and cyclin-dependent kinase 2. The genes coding for cyclin D1, cyclin D2, cyclin-dependent kinase 2 and Culin3 are stimulated by cAMP Response Element Binding Protein (CREB) and contain CREB Response Elements (CREs) in their regulatory regions. We demonstrate, by Chromatin Immunoprecipitation (ChIP) assay, that in mice with the THRA K2830/K288R mutant there was reduced CREB binding to the CRE. Mice with a THRA sumoylation mutant had reduced fat stores on chow and high fat diets and reduced adipocyte diameter.

Thyroid hormone (TH) and its receptor (THR) play an important role in embryonic development by stimulating cell proliferation and differentiation. A range of models, including frog, mouse, and zebrafish, have shown key roles for TH/THR signaling in development of the brain, retina, inner ear, heart, intestine and bone ${ }^{1}$. In postnatal development and adulthood, THR/TH regulatory networks impact the balance of stem cell proliferation and differentiation, which are essential for tissue renewal and regeneration after injury $\mathrm{y}^{2,3}$.

White adipose tissue (WAT) originates from embryonic mesoderm. Adipose precursor cells (preadipocytes) proliferate and differentiate to maintain adipose tissue homeostasis. The metabolic impact of WAT depots in humans varies by location, with upper-body subcutaneous and visceral fat associated with insulin resistance and greater risk of cardio-metabolic diseases and lower-body subcutaneous femoral and gluteal fat metabolically protective $e^{4}$. Clinical studies have shown the importance of preadipocytes in maintaining adipose tissue and adipocyte turnover is a characteristic of healthy adipose tissue. It has been reported that the fraction of preadipocytes in fat stores is reduced in obesity ${ }^{5-7}$. THRA/TH plays an important role in the regulation of adipose stores stimulating lipolysis and lipogenesis as well as mediating $\mathrm{TH}$ and adrenergic signaling in $\mathrm{fat}^{8-12}$.

Posttranslational modification of THR by SUMO directly alters THR interaction with transcription factors and modulates transcription independent of ligand ${ }^{13}$. THRA has two sumoylation sites at lysine 283 and lysine 389. An alternate sumoylation site is at lysine 288 , if lysine 283 is blocked. We have previously shown that mutation of the sumoylation sites in THRA and THRB reduce gene expression of Wnt ligand and alter the canonical $\mathrm{Wnt} / \beta$-catenin signaling pathway, which reduces adipocyte proliferation and adipogenesis in a T3-independent

${ }^{1}$ Division of Endocrinology, Diabetes and Metabolism, Departments of Medicine and Physiology, David Geffen School of Medicine at UCLA, and Veterans Affairs Greater Los Angeles Healthcare System, Los Angeles, CA 90073, USA. ${ }^{2}$ Present address: Department of Endocrinology, Zhongshan Hospital, Fudan University, Shanghai 200032, China. ${ }^{3}$ Present address: Department of Endocrinology, Union Hospital, Fujian Medical University, Fuzhou 350001, China. ${ }^{4}$ Present address: Department of Pediatrics, Keio University School of Medicine, Tokyo 160-8582, Japan. ${ }^{5}$ Present address: Saiseikai Central Hospital, Tokyo 108-0073, Japan. ${ }^{\varpi}$ email: yyl@g.ucla.edu; gbrent@ mednet.ucla.edu 
fashion $^{14}$. An in vivo model of desumoylated THRB shows disruption of thyroid stimulating hormone (TSH) regulation in the pituitary and thyroid hormone synthesis in the thyroid gland, both triiodothyronine (T3)independent ${ }^{15}$. Desumoylated THRB disrupted transcription factor binding to the TSH beta gene promoter and reduced cAMP-response element binding protein (CREB) binding to thyroid hormone synthesis genes.

In the present study, we investigated the in vivo role of THRA sumoylation, using THRA K283Q/K288R sumoylation mutant mice and human primary preadipocytes. Mice with the THRA K283Q/K288R mutation had reduced fat stores on chow and high fat diets, as well as reduced adipocyte cell diameter. Preadipocyte proliferation was reduced in human preadipocytes and in THRA K283Q/K288R mutant mice using in vivo and in vitro labeling approaches. Mice with the desumoylated THRA had disruptions in cell cycle $\mathrm{G}_{1} / \mathrm{S}$ transition and this was associated with a reduction in the availability of cyclin D2 and cyclin-dependent kinase 2.

\section{Results}

THRA has two sumoylation sites, K283 and K389. Lysine 389 interacts with the ligand binding cavity and mutations of this site diminish ligand binding. We mutated K283 to reduce THRA sumoylation without disrupting ligand binding. Mutation of the K283 residue, however, results in a shift of the SUMO conjugation site to K288 $8^{14}$. We, therefore, generated THRA K283Q/K288R, a double mutation, to eliminate SUMO binding to this THRA domain, but retain ligand binding. The double mutation, THRA K283Q/K288R, was assessed in a functional assay with a consensus $3 \times$ Direct Repeat (DR) 4 -Thyroid Hormone Response Element (TRE)-Luciferase (Luc) reporter. The magnitude of T3-induction with THRA K283Q/K288R was equal to THRA alone, or a combination of wild type and mutant THRA (Fig. 1A).

Metabolic characterization of THRA K283Q/K288R mutant mice. THRA K283Q/K288R mice were generated as a global mutation (see Supplementary Fig. S1 online) and homozygosity was confirmed by sequencing (Fig. 1B). We determined the impact of the introduced THRA mutations on the extent of THRA sumoylation in subcutaneous adipose tissue, based on the size of the band on a Western blot probed with abTHRA. We found that the desumoylated THRA was increased $73 \%(\mathrm{SE} \pm 14 \%, P<0.04)$ and the sumoylated THRA reduced $34 \%$ ( $\mathrm{SE} \pm 13 \%, P<0.05$ ), in adipose tissue from the mutant, compared to Wt, mice (Fig. 1C,D and see Supplementary Fig. S2 online). These data indicate that the sumoylation site mutations significantly reduced sumoylated THRA and increased desumoylated THRA in adipose tissue in vivo, compared to Wt mice. The amount of total THRA protein, the sum of sumoylated and desumoylated THRA, was not different in THRA mutant compared to Wt mice $(3.7 \%$ of total protein in control and $3.4 \%$ in mutant, $\mathrm{P}<0.35)$. The total protein was calculated based on the amount detected by Ponceau red stain (Fig. S2). T3-dependent gene expression in adipose tissue was assessed by RNAseq and there was no significant difference in the expression of T3-responsive genes in inguinal fat in the mutant mice, compared to Wt (see Supplementary Fig. S3 online). These data indicate that are mutation strategy successfully reduced THRA sumoylation, but preserved classic T3 signaling in vivo. The serum thyroxine (T4) (Wt mice, $4.71 \mu \mathrm{g} / \mathrm{dL} \pm \mathrm{SD} 1.21$; mutant mice $4.82 \mu \mathrm{g} / \mathrm{dL} \pm \mathrm{SD} 0.83$ ), serum triiodothyronine (T3) (Wt $218 \mathrm{pg} / \mathrm{mL} \pm$ SD 22; Mutant $234 \mathrm{pg} / \mathrm{mL} \pm$ SD 49.6), and Thyroid Stimulating Hormone (TSH) (Wt $107.8 \mathrm{ng} / \mathrm{mL} \pm$ SD 28.3; Mutant $95.5 \mathrm{ng} / \mathrm{mL} \pm$ SD 25.2), were not significantly different in mutant mice compared to Wt mice (Fig. 1E). The body weight of the mutant mice was significantly lower, compared to Wt mice, beginning at age 20 weeks $(\mathrm{p}<0.037)$ (Fig. 2A). Body composition, as determined by Echo-MRI, showed that the percent body fat of the mutant mice was significantly reduced, compared to Wt mice, from age 16 weeks onward (Fig. 2A). The inguinal White Adipose Tissue (iWAT) and epididymal (Epi-WAT) fat pads from 6 weekold mice were not different in weight from mutant mice (Fig. 2B), however, the iWAT and Epi-WAT fat pads from 3 month old mutant mice were reduced $39 \%(\mathrm{p}<0.002)$ and $35 \%(\mathrm{p}<0.004)$ respectively, compared to Wt mice (Fig. 2C). The inter-scapular brown adipose tissue (iBAT) in THRA K283Q/K288R mice was not significantly different from Wt, in juveniles (6 week) or adult mice (3 months), indicating that THRA sumoylation impacted WAT, but not BAT stores. The dissected fat pads from iWAT and Epi-WAT, were smaller in size in the mutant mice compared with Wt, consistent with overall reduced body fat (Fig. 2D). Histological analysis of iWAT showed that the adipocytes in mutant mice had a smaller diameter than Wt (Fig. 2E). The adipocyte diameter was quantified from 3 mice of each genotype and the fat cell diameter in iWAT from mutant mice was significantly smaller than that from Wt mice (Fig. 2F). The serum leptin of the mutant mice was reduced to $52 \%$ of the level in Wt mice $(\mathrm{p}<0.014)$ (Fig. 2G), consistent with overall reduced body fat. The serum adiponectin level was not different between Wt and mutant mice (Fig. $2 \mathrm{H}$ ). There was no difference in fasting serum cholesterol, free fatty acid, triglycerides or insulin concentrations, comparing the mutant mice fed with chow diet at 3 months of age to Wt mice (Fig. 2I). Food intake was not significantly different in mutant compared to Wt mice (see Supplementary Fig. S4 online). The adipose tissue phenotype in the mutant mice demonstrated a distinct role of THRA sumoylation in regulating white adipocyte diameter and the size of WAT body stores ${ }^{14}$.

Influence of high fat diet on body weight and fat stores. To determine the effect of a high fat diet, we fed 7 week old mutant and wild-type mice a Western diet ( $40 \%$ of calories from fat) for 7 weeks. The body composition was measured by Eco-MRI. The mutant mice gained markedly less weight and had lower per cent body fat, compared to wild-type mouse (Fig. 3A,B). Inguinal fat stores were substantially reduced in mutant, compared to Wt mice (Fig. 3C) and the fat cell diameter was also substantially reduced in the mutant mice compared to Wt (Fig. 3D). Food intake was not significantly different between wild type and mutant mice (mean $5.88 \pm \mathrm{SD} 1.79 \mathrm{~g} /$ day/mouse vs $6.33 \pm \mathrm{SD} 1.80 \mathrm{~g} /$ day/mouse, $\mathrm{p}=0.58$ ). The difference in fat stores in mutant mice compared to Wt mice, after a high fat diet, were in the same direction as those seen on a chow diet, but the difference between mutant and Wt mice was enhanced. 


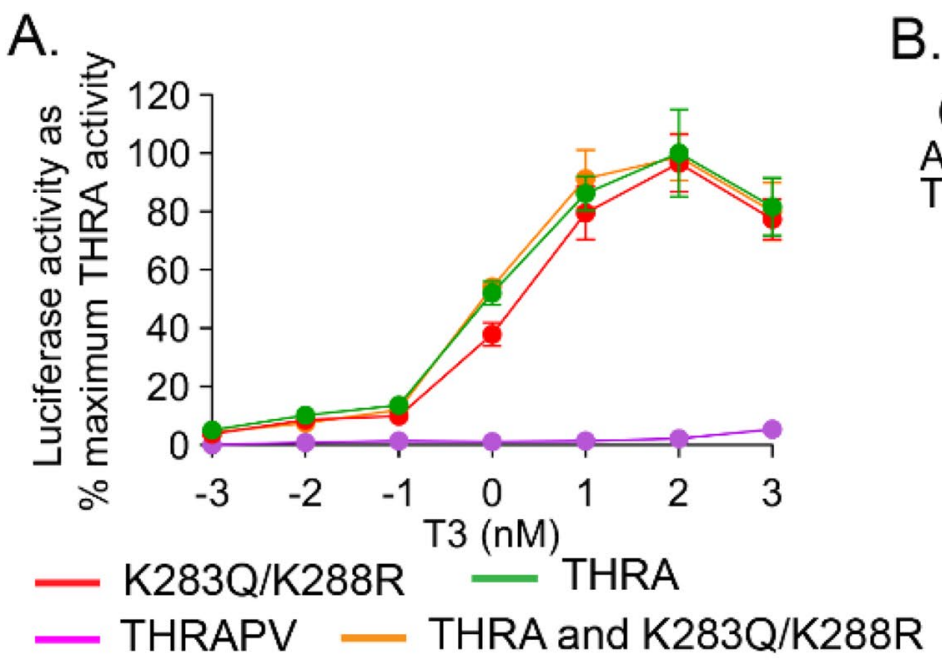

(K) (Q) (K) (R)

AAA AAG AAA ACT

TTT $\rightarrow$ TTC TTA $\rightarrow$ TGA
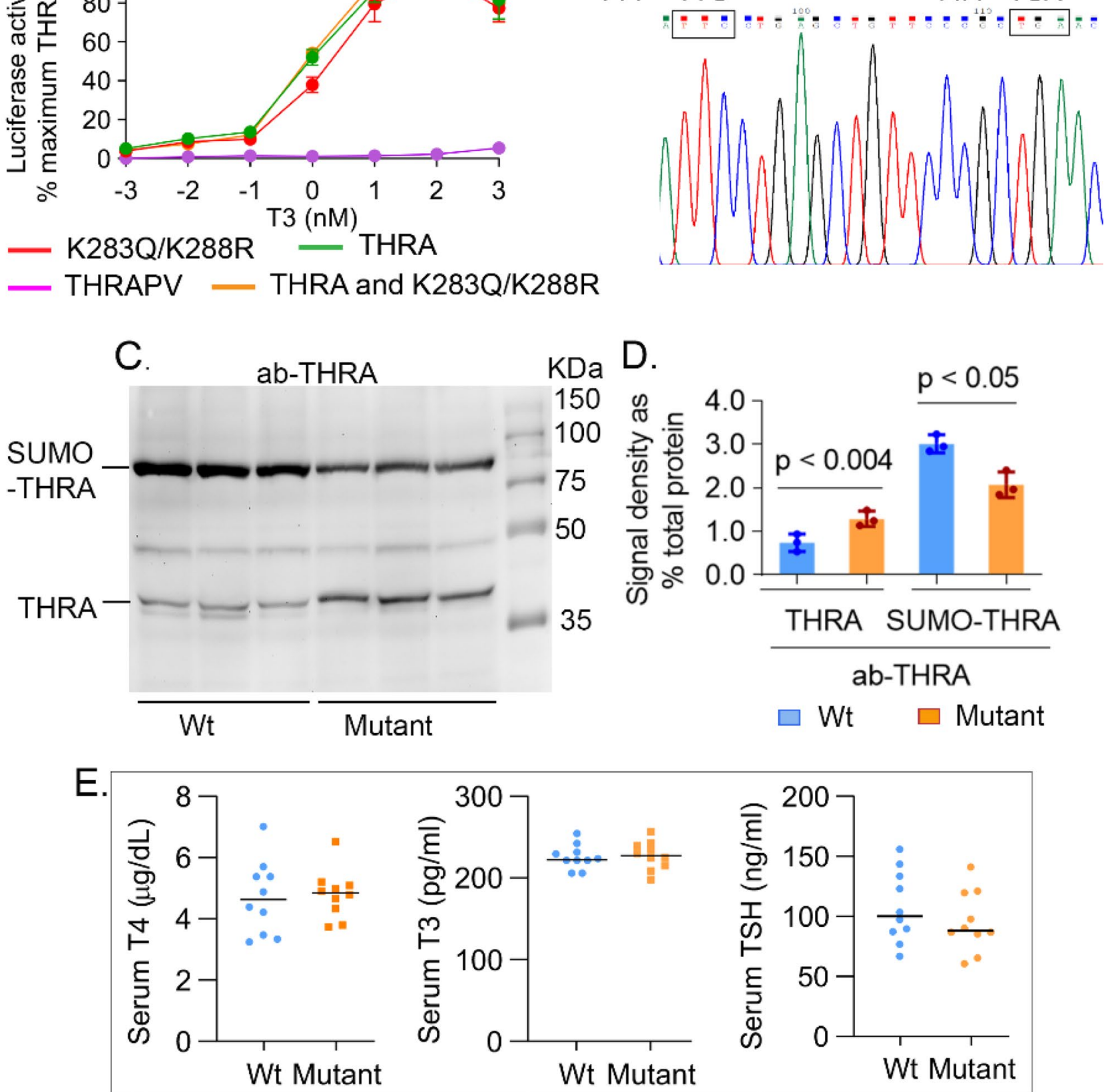

Figure 1. Genotype and thyroid function tests in THRA K283Q/K288R mutant mice. (A) A reporter assay was performed to test the T3 induction of the mutant THRA K283Q/K288R on T3-mediated luciferase reporter expression. JEG3 cells were transfected with THRA expression vectors and a luciferase reporter containing consensus $3 \times$ Thyroid Hormone Response Elements. The THRA PV mutant receptor, based on mutations in Resistance to Thyroid Hormone, was used as a negative control since it does not bind to T3. The combination of THRA with THRA $\mathrm{K} 283 \mathrm{Q} / \mathrm{K} 288 \mathrm{R}$ was used to determine dominant-negative effects of the THRA K283Q/K288R mutant receptor. (B) The presence of the mutation in homozygous THRA K283Q/K288R mutant mice was confirmed using direct DNA sequencing. (C-D) Western blot detection of THRA and sumoylated THRA, based on protein molecular weight. Subcutaneous fat was dissected from mice ( $\mathrm{n}=3$ /genotype). Protein lysate $(35 \mu \mathrm{g} / \mathrm{lane})$ was loaded on a $10 \%$ SDS gel. Antibody used was ab-THRA (C). (D) Quantification of THRA and sumoylated THRA in Western blot. The antibody detected bands and total protein (from Ponceau stained membrane, see Supplementary Fig. S2 online) were quantified using Li-Cor Image Studio lite. The data was normalized for Ponceau stained protein and presented as $\%$ total protein. Each bar in the figure represents the data from three mice. The significance was determined using Student $t$-test. (E) Fasting serum thyroxine (T4), triiodothyronine (T3) and Thyroid Stimulating Hormone (TSH) concentrations in Wt and THRA K283Q/K288R mutant mice, individual levels shown for Wild type (Wt) (circles) and mutant (squares), with a horizontal line showing the mean $(\mathrm{n}=10)$. Statistical analysis was performed by Student $t$-test. 
A.

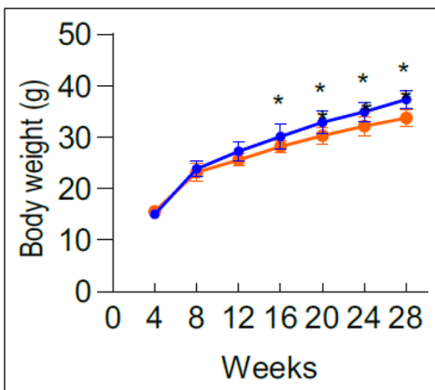

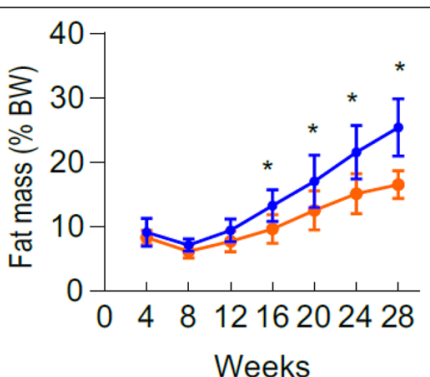

Weeks

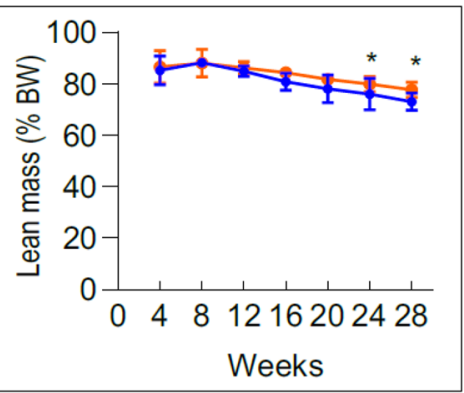

Mutant
B.

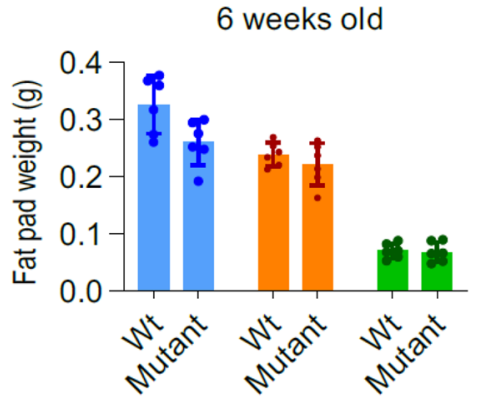

C.

\section{3 months old}

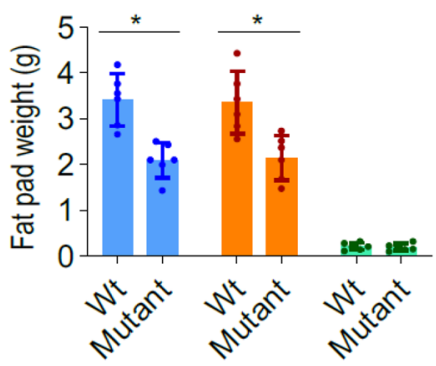

F.
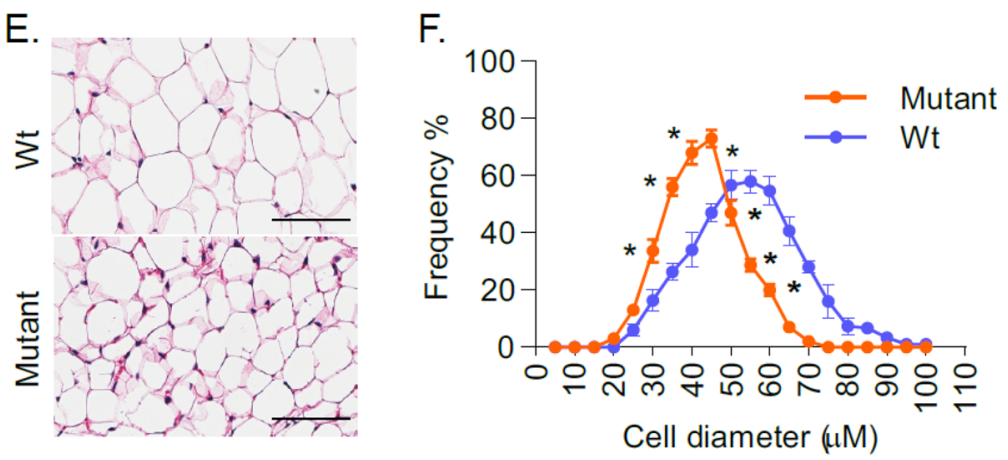

D.

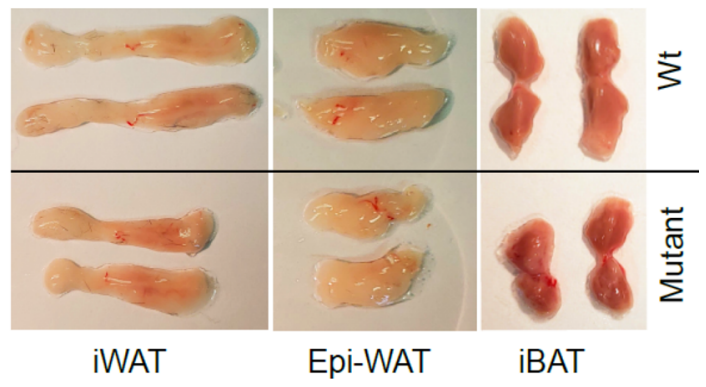

G.

$\mathrm{H}$.
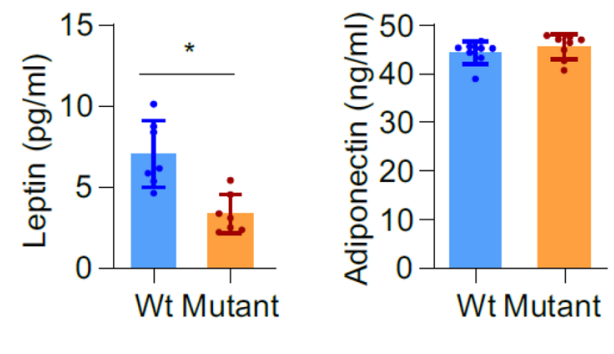

I.
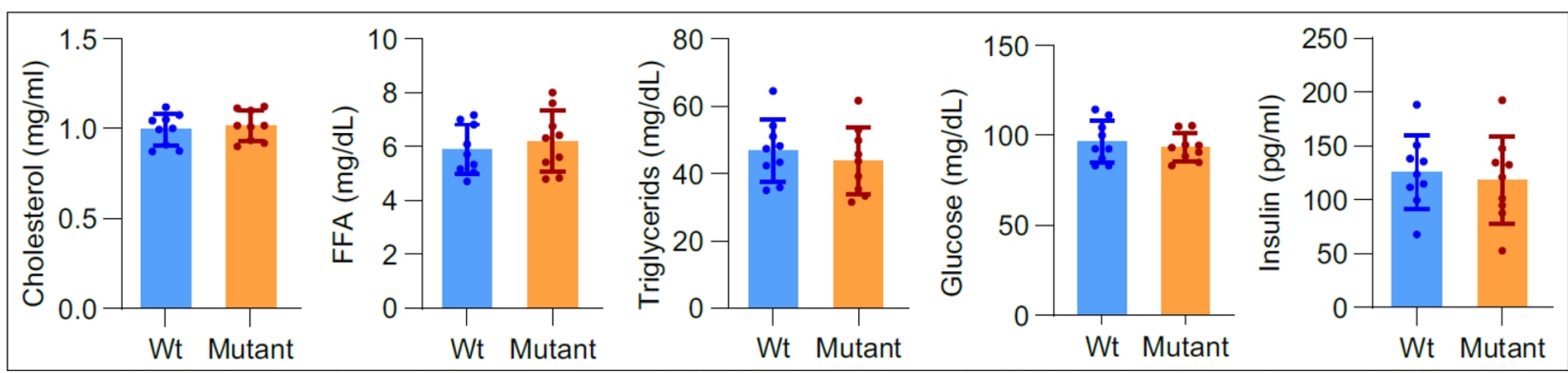

Figure 2. THRA K283Q/K288R mutant mice display body composition, fat stores, and metabolic profile. Age-matched wild type (Wt) and THRA K283Q/K288R mutant mice (mutant) were fed with chow diet. (A) Body composition was determined by Echo-MRI ( $n=9 /$ group) and average value is shown for body weight (BW), fat and lean body mass. (B) Fat pads (iWAT-inguinal White Adipose Tissue-blue bars, Epi- epididymal fat-orange bars, iBAT- inter-scapular Brown Adipose Tissue-green bars) were dissected and weighed from 6 weeks old mice $(n=6)$ and from $(C) 3$ month old mice $(n=6)$. (D) Images of dissected fat pads from 3 month old Wt and mutant mice $(n=6 /$ group), representative samples are shown. (E) Histological analysis of inguinal WAT, representative slides from wild type and mutant mice are shown (scale bar $100 \mu \mathrm{m}$ ). (F) Fat cell diameter $(\mu \mathrm{M})$ of inguinal fat was analyzed. A total of 360 cells from each genotype was quantified (see "Materials and methods" section for details). The data is shown as diameter frequency of 360 cells. (G,H) Non-fasting serum leptin and adiponectin levels ( $n=7 /$ group, 3 month old mice). (I) Fasting serum cholesterol, triglycerides, free fatty acids (FFA), insulin and glucose concentrations in 3 month old mice. The statistical analysis was performed using paired Student $t$-test. 
A.

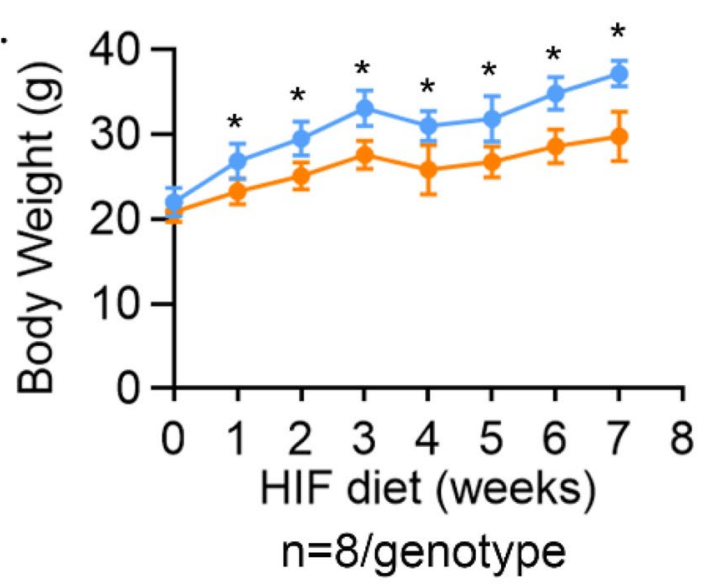

B.

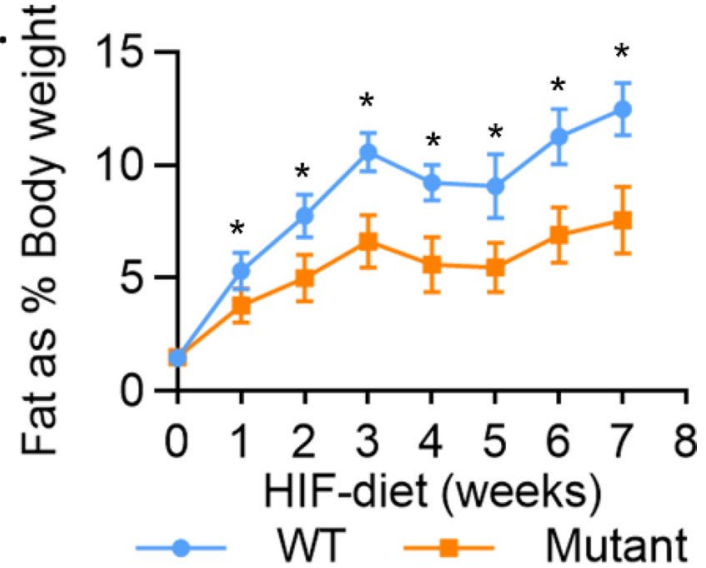

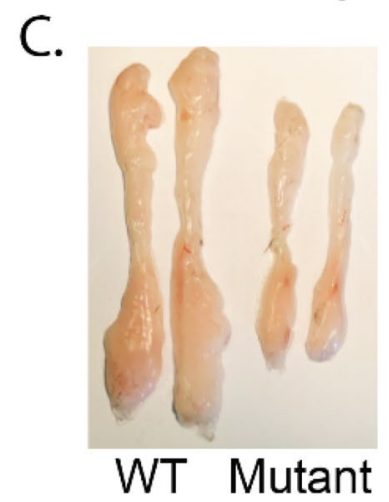

D.

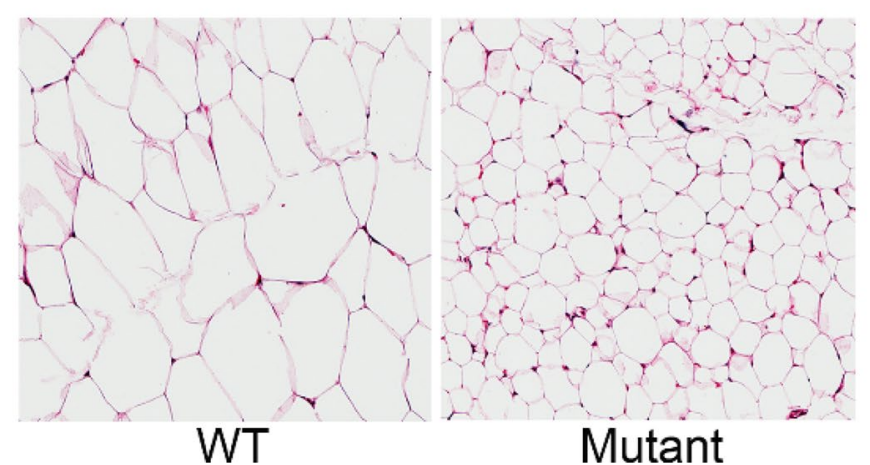

Figure 3. THRA K283Q/K288R mice are resistant to High fat diet-induced body fat increase and adipose tissue expansion. Mice ( $n=8 /$ genotype) were given High Fat (HIF) diet ( $40 \%$ fat in calories) for 7 weeks starting at age 7 weeks old. The body composition was measured by Eco-MRI. (A) Body weight and (B) body fat as \% body weight. (C) Mice were euthanized and fat pads were dissected, rinsed and photographed and representative inguinal fat depot as shown. (D) Representative histological image of inguinal fat from WT and mutant mice. The statistical analysis was perform at each time point using paired Student $t$-test.

Preadipocytes proliferation in mutant mice. We investigated whether the reduced fat mass in THRA K283Q/K288R mutant mice was associated with reduced preadipocyte proliferation. To determine the preadipocyte proliferation status in live mice, we performed EdU labeling of 3 week old mice. The EdU labeled-nuclei represent cells in S phase, a phase of active DNA synthesis. In adipose tissue, dividing preadipocytes are concentrated in the vascular stroma. The EdU labeled-nuclei were reduced $27 \% \pm \operatorname{SD} 5.2 \%(p<0.02)$ in the vascular stroma of inguinal adipose tissue in THRA mutant mice, compared to Wt mice (Fig. 4A,B). We also isolated preadipocytes from the stromal vascular fraction of iWAT from 6 week old Wt and THRA mutant mice. Cells were synchronized to $\mathrm{G}_{0} / \mathrm{G}_{1}$ cell cycle by serum withdrawal for $36 \mathrm{~h}$ and then stimulated to enter the cell cycle by addition of a $10 \%$ serum supplement. The proliferation of preadipocytes isolated from THRA K283Q/K288R mutant mice, as determined by EdU-DNA incorporation, was reduced $24.3 \% \pm \mathrm{SD} 3.7 \%(p<0.011)$ in mutant mice compared to Wt mice (Fig. 4C,D). The number of preadipocytes isolated from SVF of the iWAT of the mutant mice was reduced $23.3 \% \pm \mathrm{SD} 3.3 \%(\mathrm{p}<0.0035)$ from 3 individual experiments $(\mathrm{n}=6$ mice/experiment $)$ compared to that of Wt mice (Fig. 4E). The mRNA levels of Cyclin D1 and D2 and cyclin-dependent kinase 2 $(C d k 2)$ were reduced in the mutant preadipocytes, compared to Wt mice (Fig. $4 \mathrm{~F})$.

THRA sumoylation-defective mutant K2830/K288R reduces nuclear localization of cyclin D1, cyclin D2, Cdk4 and Cdk2 in human primary preadipocytes. The influence of the sumoylation defective THRA on proliferation was studied in human primary preadipocytes cells, transfected with plasmids expressing THRA, THRA K283Q/K288R, or an empty vector (control), synchronized to $\mathrm{G}_{0}$ by serum withdrawal for $48 \mathrm{~h}$. Serum withdrawal resulted in more than $75 \%$ of the cells synchronized to $\mathrm{G}_{0}$ phase, as assessed by flow cytometry. Serum withdrawal prolonged the $G_{1}$ and $S_{1}$ phases, compared to growth in serum conditions, due to recovery from the lower cellular metabolism associated with serum starvation ${ }^{16}$. Cells were, therefore, supplemented with serum for $9 \mathrm{~h}$ and analyzed for the expression of $\mathrm{G}_{1}$ phase regulators. In the $\mathrm{G}_{1}$ phase, cyclin D1 forms a complex with cyclin-dependent kinase 4 (Cdk4) The cyclin D1/Cdk4 complex is then transported from the cytoplasm to the nucleus by p27kip Cdk inhibitor ${ }^{17}$. In cells transfected with THRA K283Q/K288R, compared to those transfected with empty vector (control) and THRA, the immunofluorescent (IF) staining demonstrated that Cdk4 protein was predominantly in the cytoplasm but not the nucleus (Fig. 5A). The cell lysate was fractionated into cytoplasmic and nuclear fractions and immunoprecipitated (IP) with antibodies against 
A.

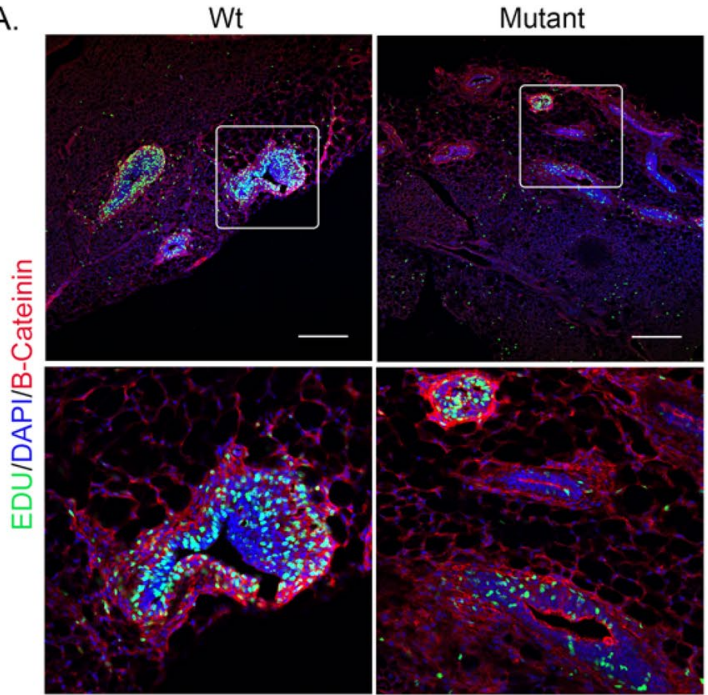

B.

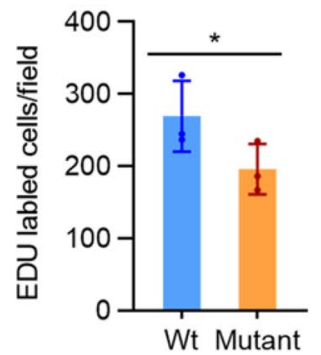

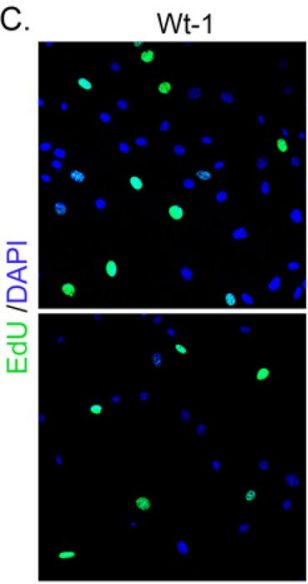

Mutant-1

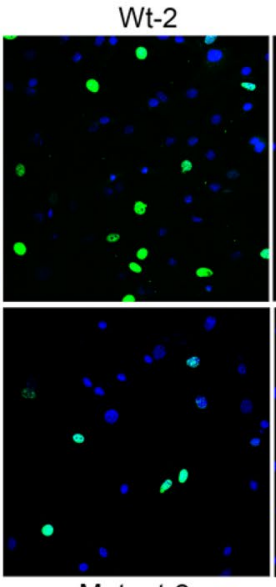

Mutant-2

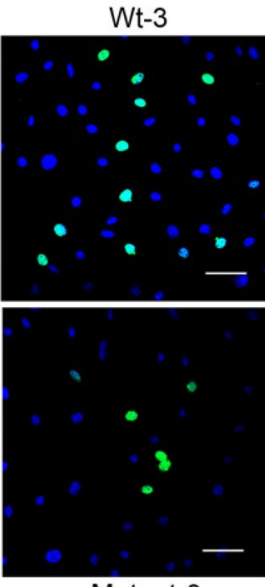

Mutant-3
D.

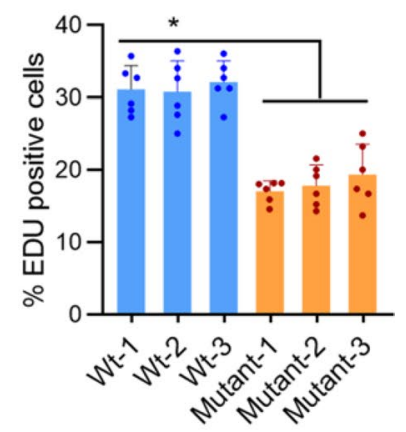

E.

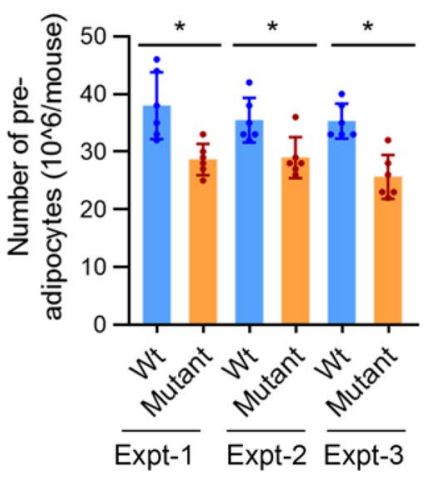

F.

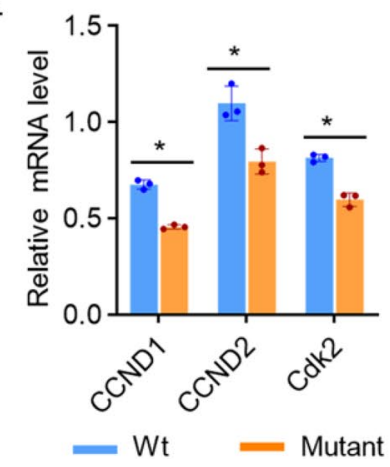

Figure 4. Preadipocyte proliferation in mutant mice determined in vivo and in vitro. (A,B) EdU labeling of proliferating preadipocytes in 3 week old mice. Mice were given EdU, $5 \mu \mathrm{g} / 100 \mathrm{~g}$ body weight (i.p.) and inguinal fat pads were isolated and fixed in $4 \%$ paraformaldehyde $12 \mathrm{~h}$ after injection. Frozen sections ( $12 \mu \mathrm{M}$ thickness) of inguinal fat depots were stained with $\beta$-catenin (red) for cell membrane and DAPI (blue) for nuclei. EdU (Green) incorporation of DNA in dividing cells was detected by Click-IT chemistry. (A) EdU incorporation was imaged using confocal microscope and representative sections of regions with stromal vascular regions are shown. Lower panel shows enlarged view of the area as indicated. The scale bar is $200 \mu \mathrm{M}$. (B) EDU incorporation was quantified in three different sections using a $\times 20$ magnification field. (C) Isolated preadipocytes proliferation. Preadipocytes were derived from the stromal vascular fraction of fat from 6 week old wild type (Wt) and mutant mice ( $n=6 /$ group). Preadipocytes from each mouse were plated on separate plates and synchronized as described in the "Materials and methods" section. After synchronization, cells were supplemented with $10 \%$ serum and labeled with EDU for $4 \mathrm{~h}$, followed by fixation and imaging. Representative images from 3 separate experiments are shown. Scale bar is $50 \mu \mathrm{M}$. (D) Quantification of EDU positive cells (green color) and nuclei imaged with DAPI (blue). (E) Quantification of the number of SVF-derived preadipocytes. For each experiment ( $\mathrm{n}=6$ mice). The data shown is the average numbers of preadipocytes in each experiment. (F) q-PCR analysis of Cyclin D1 (CCND1), Cyclin D2 (CCND2) and cyclindependent kinase 2 (Cdk2) mRNA levels, obtained from expression PCR array and normalized for four housekeeping genes. Please see "Materials and methods" for quantification shown in (B) and (C). ${ }^{*}, \mathrm{p}<0.05$ compared to wild type mice. 
A.

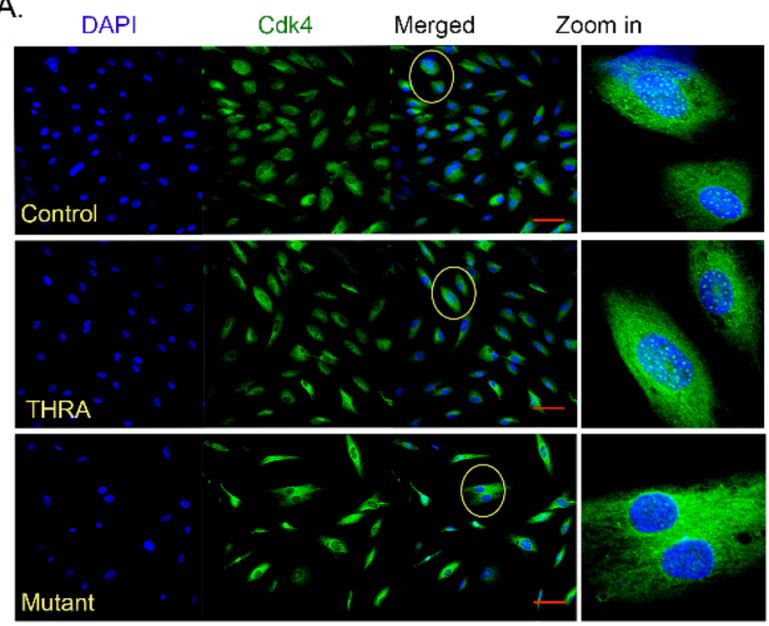

B.

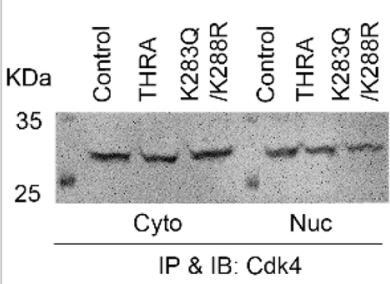

C.

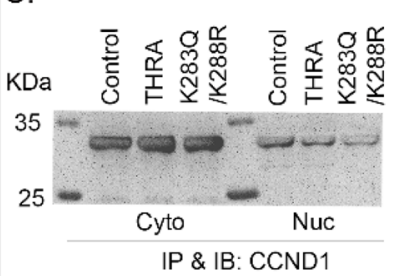

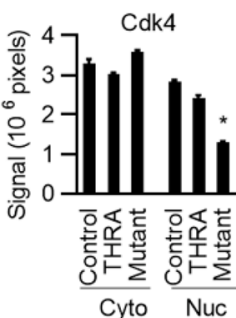

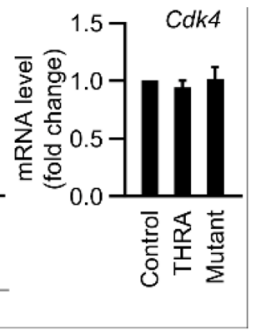

CCND1

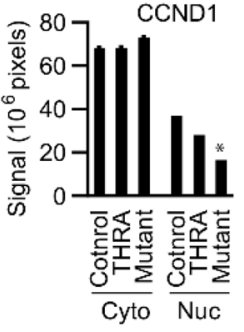

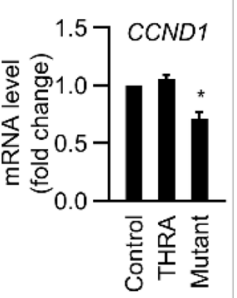

Figure 5. Mutation of the THRA sumoylation site, K283Q/K288R, associated with reduced nuclear localization of cyclin D1-Cdk4 complex, cyclin D2 and Cdk2 in $\mathrm{G}_{1}$ phase. (A) Human preadipocytes were transfected with empty vector (control) or plasmids expressing THRA or THRA K283Q/K288R. Cells were synchronized to $\mathrm{G}_{0} /$ $\mathrm{G}_{1}$ phase by serum starvation for $48 \mathrm{~h}$. Cells were then allowed to re-enter the cell cycle by supplementing the medium with $10 \%$ calf serum. After $9 \mathrm{~h}$ of serum supplementation, the cells were analyzed for nuclear content of cyclin D1-Cdk4 complex, cyclin D2 and Cdk2. Immunofluorescent (IF) staining of cyclin D1 and Cdk4 nuclear localization in cells. Scale bar, $50 \mu \mathrm{m}$. Circled inset shows higher magnification. (B) The nuclear and cytoplasmic fractions were analyzed for Cdk4 protein expression by IP with anti-Cdk4 Ab, followed by immunoblot (IB) with anti-Cdk4 and quantified Cdk4 IB signals using Li-Cor Image Studio Lite. (C) Co-IP detection of cyclin D1 in the cytoplasm and nuclear fractions. Anti-p27kip antibody was used in IP and anti-cyclin D1 antibody in IB. Quantification of WB was done using Image Studio Lite. q-PCR quantification of Cdk4 and cyclin D1 (CCND1) mRNA expression, presented as the mean value and $\mathrm{SD}$, fold above control. ${ }^{*} \mathrm{p}<0.05$ compare to control by One-way Anova. IP-immunoprecipitation, IB-immunoblot. The blots $(\mathbf{B}, \mathbf{C})$ were cut prior to hybridization and the origin blots are provided (see Supplementary Fig. S7 online).

Cdk4 in order to quantitate the subcellular distribution of Cdk4. The quality of fractionation was confirmed by alpha tubulin staining for the cytoplasmic fraction and lamininB1 for the nuclear fraction (see Supplementary Fig. S5 online). In the cytoplasmic fraction, Cdk4 was similar among different samples. In the nuclear fractions, Cdk4 was reduced in cells expressing THRA K283Q/K288R, compared to control and THRA-transfected cells (Fig. 5B). Cdk4 enters the nucleus in the form of a cyclin D1/Cdk4 complex, carried by p27 kip, so the reduced nuclear Cdk4 could be the result of reduced nuclear cyclin D1. To investigate this possibility, we performed a co-IP with anti-p27 kip and WB with anti-cyclin D1. We found that in the cells transfected with THRA K283Q/ K288R, p27 kip-bound nuclear cyclin D1 was only 45\% of the control levels (Fig. 5C). Cyclin D1 mRNA was reduced $28 \%(\mathrm{p}<0.033$ ) but $C D k 4 m R N A$ was not changed (Fig. 5B,C far right panels), indicating that reduction of the cyclin D1/Cdk4 complex is associated with reduced cyclin D1 gene expression.

Cyclin D2 is a $G_{1} / S$ phase-specific cyclin and forms a complex with Cdk4/6 that mediates the $G_{1} / S$ transition. We detected reduced nuclear cyclin D2 protein by immunofluorescence and IP of cytoplasmic and nuclear fractions in THRA K283Q/K288R-transfected cells, compared to THRA and control (Fig. 6A-C). Cyclin D2 mRNA was decreased $36 \%$ in mutant cells compared to control ( $\mathrm{p}<0.034$ ) (Fig. 6D). Cdk2 is another important factor regulating the $\mathrm{G}_{1} / \mathrm{S}$ phase transition. Cdk2 moves into the nucleus and, together with Cdk4, sequentially phosphorylates retinoblastoma protein $(\mathrm{Rb})$. Cdk2, as shown by immunofluorescence staining and IP, localized to the nucleus in control and THRA-transfected cells. In THRA K283Q/K288R-tranfected cells, however, there was significantly less Cdk2 protein in the nucleus (Fig. 6E-G). Cdk2 mRNA levels were reduced 20\% in THRA K283Q/K288R-transfected cells (Fig. 6H), indicating that reduced nuclear Cdk2 protein was associated with impaired Cdk2 gene expression and reduced nuclear translocation. These data show that expression of THRA $\mathrm{K} 283 \mathrm{Q} / \mathrm{K} 288 \mathrm{R}$ is associated with slowing of the $\mathrm{G}_{1} / \mathrm{S}$ transition. We observed reduced nuclear localization of the cyclinD-Cdk complex and reduced mRNA levels of the cell cycle regulating genes, Cyclin D1, Cyclin D2 and Cdk2 in the G1 phase.

Delayed $G_{1} / S$ transition. We performed cell cycle analysis by Flow Cytometry to evaluate S-phase entry (Fig. 7A). Cells were synchronized by serum withdrawal and then cells were released to the $G_{1}$ phase by serum supplementation. At baseline, $0 \mathrm{~h}$ (before adding serum), the number of cells in $\mathrm{G}_{1}$ phase was not significantly different among the different plasmid-transfected cells (Fig. 7B). The fraction of cells in S phase, $16 \mathrm{~h}$ after serum supplementation, was $44.7 \%$ in control and $47.5 \%$ in THRA-expressing cells, but reduced to $37.5 \%(p<0.01)$ in cells expressing THRA K283Q/K288R (Fig. 7C). The S phase lag persisted at $24 \mathrm{~h}$ in THRA K283Q/K288Rtransfected cells, compared to control and THRA-transfected cells. The late S-phase entry delayed DNA synthesis and the expansion of cellular content, resulting in a reduced proliferation rate. 
A.

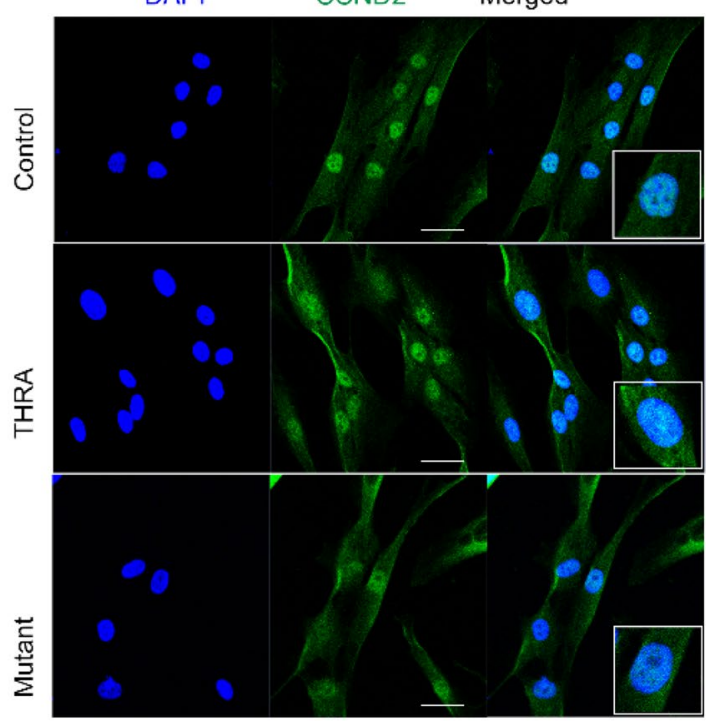

B.

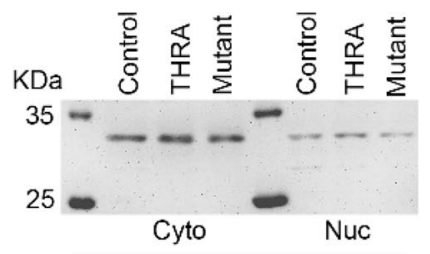

IP \& IB: CCND2
C.

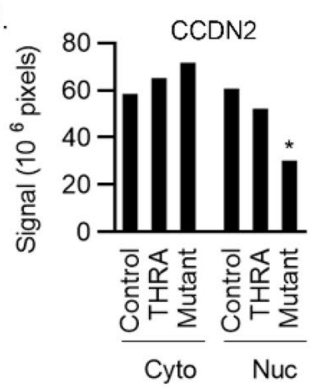

D.

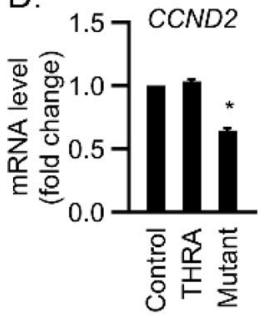

E

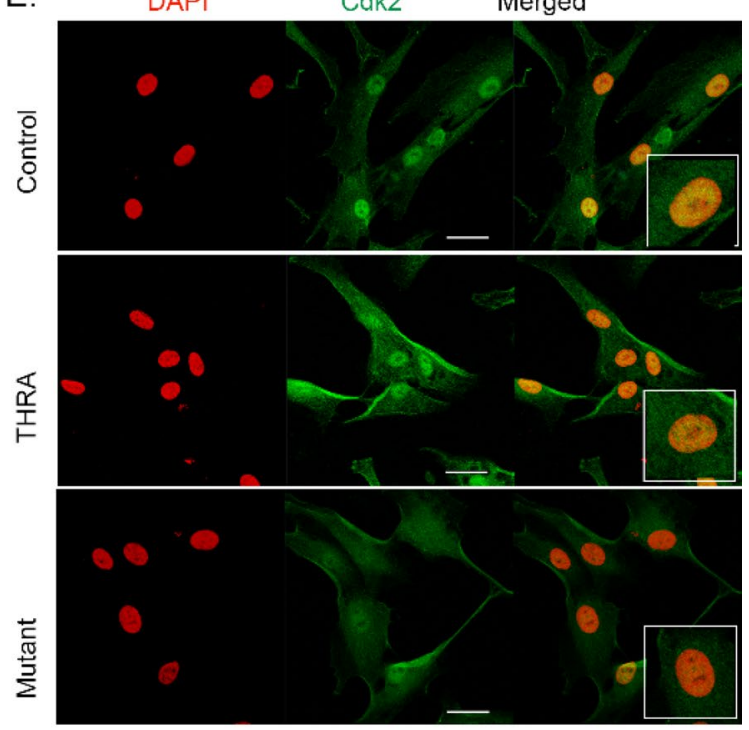

F.

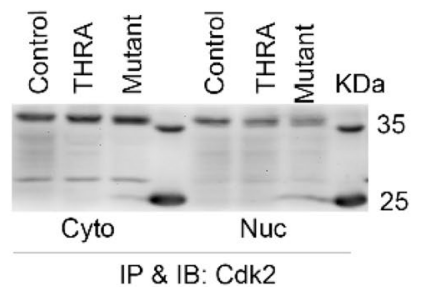

G.

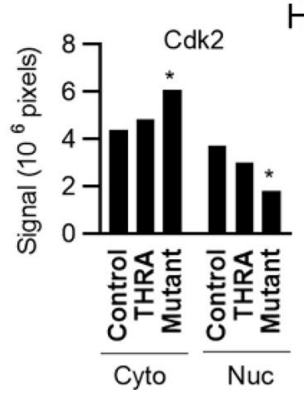

$\mathrm{H}$.

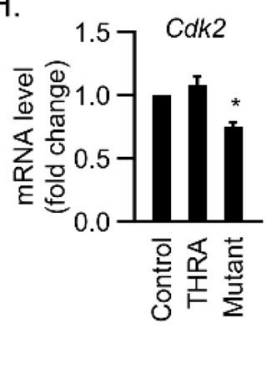

Figure 6. Nuclear localization of Cyclin D2 and Cdk2 in human primary preadipocytes expressing THRA K283Q/K288R. Cell treatment and conditions are the same as described in the Fig. 4 legend. (A,E) IF detection of nuclear cyclin D2 (CCND2) and Cdk2 protein with DAPI stain of nucleus. Circled inset shows higher magnification. (B,F) detection of nuclear CCND2 and Cdk2 protein using IP and followed by IB with anticyclin D2 antibody and anti-Cdk2 antibody, and quantified by Li-CoR Imaging Studio lite (C,G). (D,H) q-PCR analysis of CCND2 and Cdk2 mRNA and fold-change from control is shown. Primers were pre-designed (Qiagen). ${ }^{*} \mathrm{p}<0.05$ as statistically significant by One-way Anova for qPCR data, and by Two-way Anova for IB quantification Scale bar, $50 \mu \mathrm{m}$. The blots (panels B and F) were cut prior to hybridization and the origin blots are provided (see Supplementary Fig. S8 online).

Influence of the THRA K2830/K288R on CREB- and AP1-mediated gene expression. To determine in an unbiased fashion the signaling pathways disrupted by the desumoylated THRA, we screened the transcription factors important in the $\mathrm{G}_{1}$ phase regulation, using a functional reporter assay. CREB, P53, C-myc, SMAD, FoxO1, SP1 and AP1 are critical transcription factors for expression of genes important for cell cycle regulation ${ }^{18-30}$. CREB, C-myc, SP1 and AP1 are positive regulators of cell cycle progression ${ }^{30-33}$ and P53, SMAD and FoxO1 are negative regulators, promoting cell cycle exit ${ }^{34-36}$. We used luciferase reporters carrying multiple (6x) consensus response elements for each transcription factor and determined the functional activity of these transcription factors in cells transfected with empty vector (control), and vectors expressing THRA and THRA K283Q/K288R. The luciferase activity was not different between control and THRA-transfected cells for all transcription factor studied. However, in THRA K283Q/K288R-transfected cells, luciferase transcription-mediated by CREB and AP1 were reduced $46 \%(\mathrm{p}<0.05)$ and $53 \%(\mathrm{p}<0.05)$, respectively and P53 and SP1 were increased $31 \%(\mathrm{p}<0.05)$ and $53 \%(\mathrm{p}<0.05)$, respectively, compared to control cells (Fig. 8A). The transcription activity mediated by c-Myc, SMAD and FoxO1 was barely detectable. CREB, AP1 and SP1 are known to regulate the expression of CCND1 (cyclin D1), CCND2 (cyclin D2) and Cdk2 and the response elements for these factors have been identified ${ }^{19,22,27}$. THRs has been previously shown to antagonize CREB-mediated transcription ${ }^{37-39}$. Based 
A.

Control
empty vector

Oh

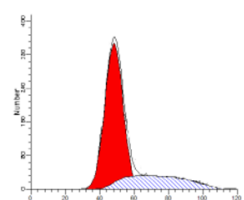

$8 \mathrm{~h}$

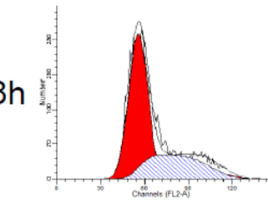

$16 \mathrm{~h}$
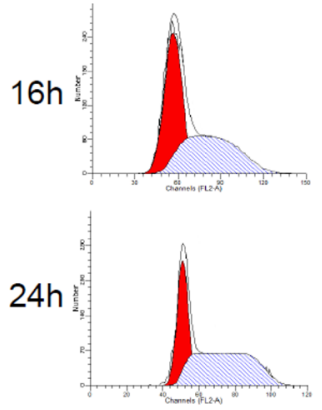

THRA transfected
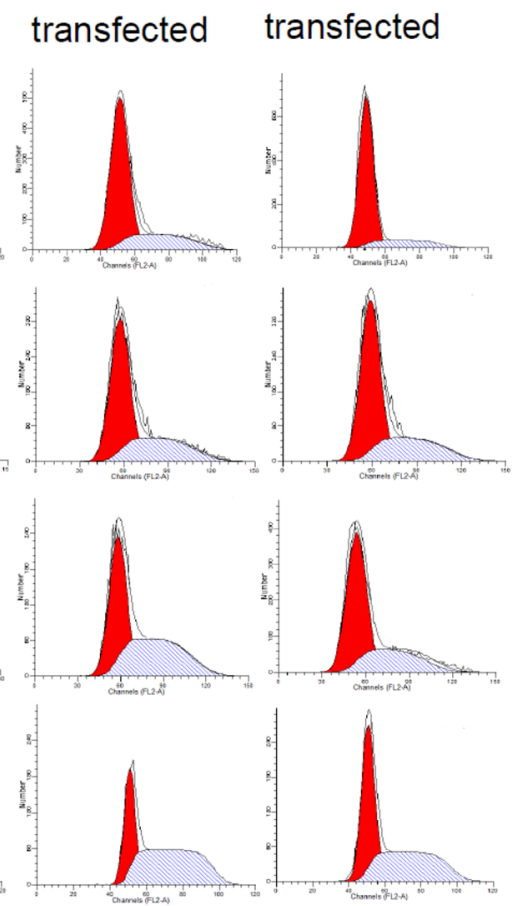
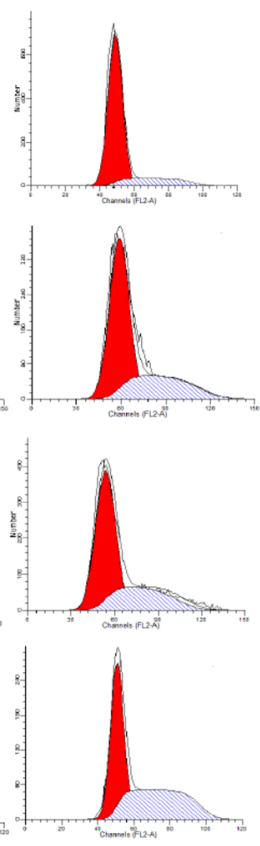

B.

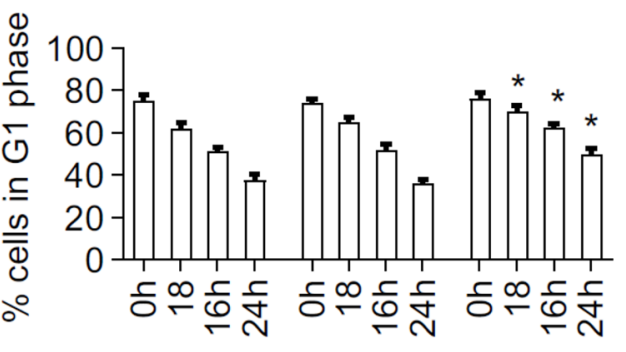

Control THRA K283Q/K288R

Figure 7. Analysis of cell cycle progression in human preadipocytes. (A) Cell cycle progression was analyzed by Propidium iodide Flow Cytometer. Cell synchronization is the same as describe in the Fig. 4 legend. After serum starvation, cells were supplemented with $10 \%$ serum for a period of $0,8,16,24 \mathrm{~h}$. At each time point, cells were collected and analyzed by flow cytometry. Percentage of cells in $\mathrm{G}_{1}$ phase $(\mathbf{B})$ and $\mathrm{S}$ phase $(\mathbf{C})$, obtained from flow cytometry for each time point is shown. ${ }^{\star} \mathrm{P}<0.05$ as statistically significant compared with control and THRA at the same time point by One-way Anova analysis.

on these findings, we focused on the effects of the desumoylated THRA on CREB-mediated transcription for these key cell cycle genes.

Altered THRA-CREB interaction in preadipocytes isolated from THRA K2830/K288R mutant mice. THR does not bind directly to the CREB response element (CRE) but has been shown, in previous studies, to interact with CREB, as demonstrated by pull-down and co-IP assays ${ }^{37,40,41}$. We postulated that the sumoylation-defective THRA K283Q/K288R influenced protein-protein interactions between THRA and CREB, resulting in reduced expression of cell cycle genes. There are four potential CREs in the mouse CCND1 gene, numbered CCND1-site1 to- site 4, equivalent to the human orthologue CCND1 gene ${ }^{32,42}$. To detect the influence of THRA K283Q/K288R on protein-DNA and protein-protein interaction, we isolated preadipocytes from THRA K283Q/K288R mutant and wild type mice (abbreviated as mutant-preadipocytes and wt-preadipocytes). The mouse preadipocytes were synchronized by serum withdrawal for $36 \mathrm{~h}$ and then cultured with $10 \%$ serum for $8 \mathrm{~h}$ prior to harvesting nuclear protein for the ChIP assay. The initial ChIP assay, using anti-CREB antibody, showed that CREB bound to two of the four putative CREs (CCND1-site1 and CCND1-site2) in the $\mathrm{G}_{1}$ phase (Table1). In the remainder of the studies, only these two active sites were evaluated. In addition, the effects of THRA on CREB binding to CREs in the CCND2, Cdk2 and Cullin3 (Cul3) gene promoters were investigated by ChIP assay (Table 1).

CREB enrichment to the CCND1-site 2 was 7 -times greater than that to CCND1-site 1 in wt-preadipocytes, indicating that the CCND1-site 2 is the primary CREB binding site (Fig. 8B,C). THRA from Wt-preadipocytes did not interact with CREB in either CCND1-site1 or site2 (Fig. 8B,C, orange bars). In mutant-preadipocytes, a very small amount of CREB was enriched to the CCND1-site1 and none to the CCND1-site 2. The THRA K283Q/K288R from mutant preadipocytes had significant enrichment (7.8\%) to the CCND1-site 2 (Fig. 8C), indicating THRAK283Q/K288R is associated with reduced CREB DNA-binding.

The Cdk2 gene contains two potential CREs, but only one site had detectable CREB binding in our initial ChIP assays, which is referred as Ckd2 CRE (see Table 1 for location and sequence). In Wt-predipocytes, both THRA and CREB, were enriched at the Cdk2 CRE with similar enrichment, 1.3\% and $1.2 \%$, respectively (Fig. 8D). In mutant-preadipocytes, overall enrichment of CREB and THRA K283R/K288Q to this site was significantly reduced to $0.093 \%$ and $0.26 \%$ respectively. We speculate that fully sumoylated THRA facilitates CREB DNA binding on CDK2 CRE and THRA K283Q/K288R reduced CREB binding to the site. In the CCDN2 gene promoter region, low CREB enrichment was detected and THRA enrichment was negligible (Fig. 8E). Although the CCND2 mRNA levels was reduced in mutant preadipocytes, it was not due to reduced activation by CREB but may be the result of reduced AP1. There is an AP1 binding site located in the CCND2 promoter ${ }^{23}$. THRB is 


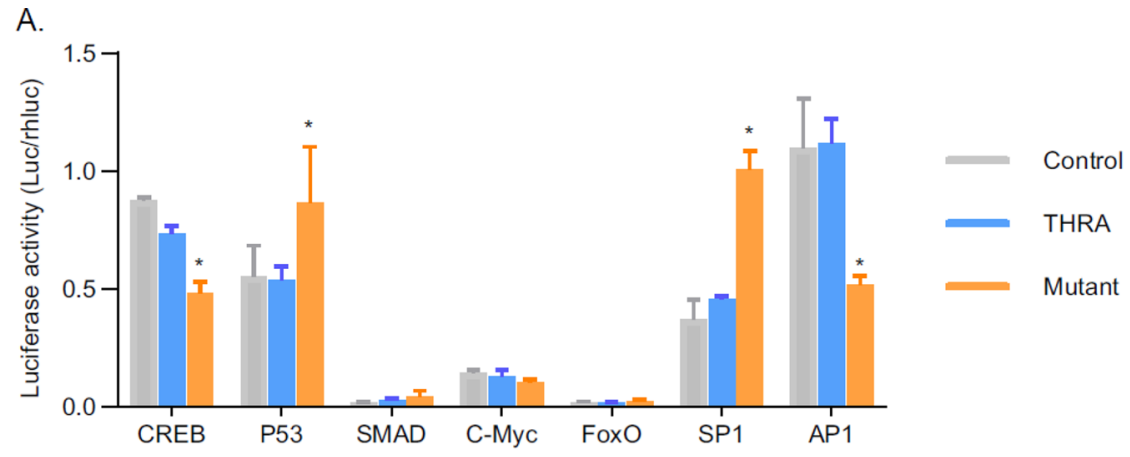

B.

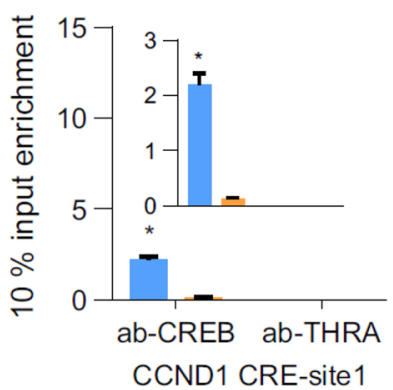

F.

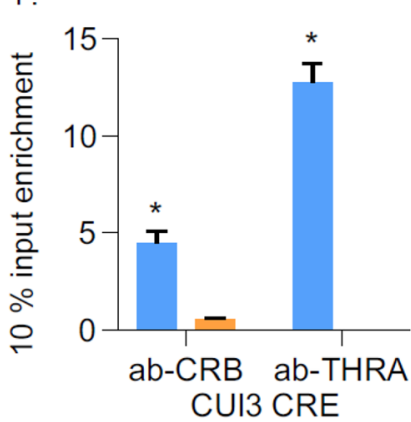

J.
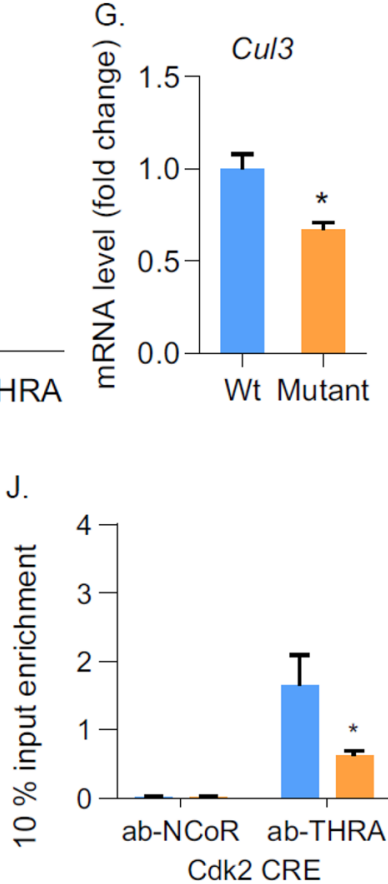

D.

E.
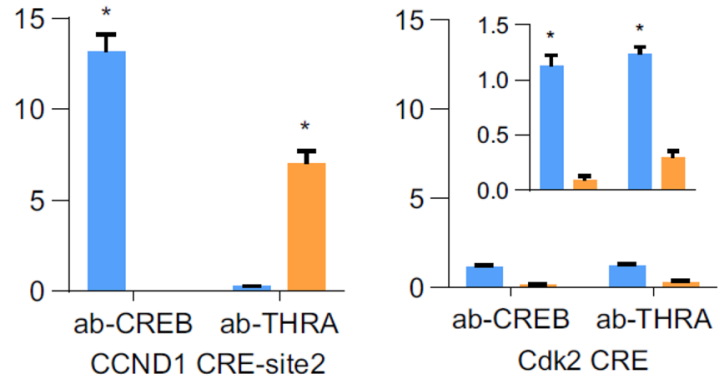

$\mathrm{H}$.

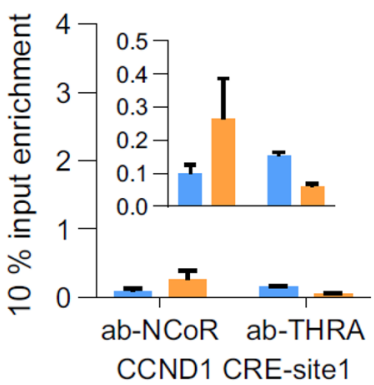

I.
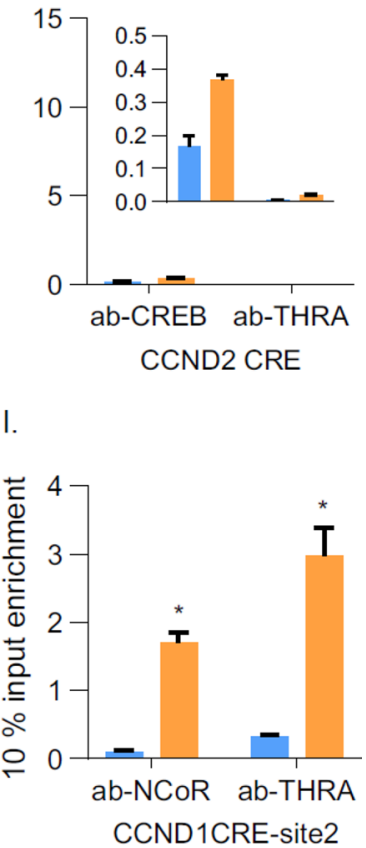

$\mathrm{K}$.

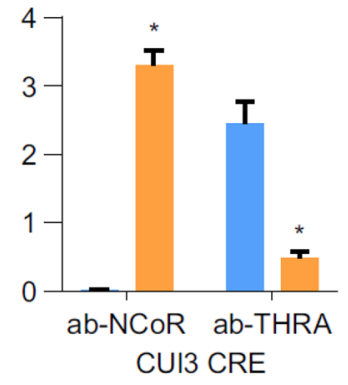

Wt

Mutant

Figure 8. Expression of THRA K283Q/K288R associated with altered CREB binding to the cAMP Response Element (CRE) of cell cycle regulatory genes. (A) Human preadipocytes were transfected by electroporation with luciferase reporter containing multiple copies of a response element for each transcription factor tested. Each transfection had 6 replicates and the data shown is the average with SD. Statistical analysis was formed using One-way Anova. (B-F) ChIP analysis of CREB-THRA interaction on CREs. Preadipocytes were isolated from wild type mice and mutant mice. After synchronization, cells were supplied with serum for $8 \mathrm{~h}$ prior to harvest for ChIP assays of CRE on CCND1, CCND2 and Cdk4 promoter. For Cul3 gene promoter, cells were supplemented with serum for $12 \mathrm{~h}$. (G) q-PCR analysis of Cul3 gene expression in cells supplied with $12 \mathrm{~h}$ of serum after synchronization. (H-K) ChiP assay of THRA requirement of Nuclear Co-Repressor (NCoR) effects on CREs. The antibodies used were anti-THRA, anti-CREB, and anti-NCoR. PCR was performed for 35 cycles. Normal rabbit IgG was used as the negative control in ChIP assays. All ChIP data shown are after deducting the negative control and expressing as \% input enrichment. Input was $10 \%$ of total pre-cleared lysate. Statistical analysis was performed using Student $t$-test. CREB, cAMP response element binding protein; P53 tumor suppressor protein, $c-M y c$ cellular homolog of myc oncogene, FoxO1 forkhead box protein 1, Sp1 specificity protein $1, A P 1$ activator protein 1 . 


\begin{tabular}{|c|c|c|c|c|c|c|}
\hline Gene & TF & Chr & TF-BS position (chr) & ChIP q-PCR length (bp) & ChIP detection & Primers for $\mathrm{qPCR}$ \\
\hline CCND1 & CREB & 7 & 152123548 & 179 & No & $\begin{array}{l}\text { F: } 152123639 \text { 5'-caccatgtctgtggtgaaac- } \\
\text { cact } \\
\text { R: } 152123460 \text { 5'-gtgcctctagaaatac- } \\
\text { taaggggac }\end{array}$ \\
\hline CCND1 & CREB & 7 & 152124370 & 170 & No & $\begin{array}{l}\text { F: } 1521244905 \text { 5'-gatgtccactgagctcctgac } \\
\text { R: } 152124320 \text { 5'-gcgagacacaatggtggcgt }\end{array}$ \\
\hline CCND1 & CREB & 7 & 152125045 & 165 & Yes & $\begin{array}{l}\text { F: } 152125140 \text { 5'-tgcaggctgagcttctgtgg } \\
\text { R: } 152124975 \text { 5'-ataatattggcacgagcg- } \\
\text { gcc }\end{array}$ \\
\hline CCND1 & CREB & 7 & 152128311 & 170 & Yes & $\begin{array}{l}\text { F: } 152128350 \text { 5'-gacctttcaagttgccgccag } \\
\text { R: } 152128209 \text { 5'-aggaaccctcgcgactaagc }\end{array}$ \\
\hline Cdk2 & CREB & 10 & 128137056 & 107 & Yes & $\begin{array}{l}\text { F: } 128137124 \text { 5'- gaggcagaggcagttggat } \\
\text { R: } 128137027 \text { 5'-ccagagagaatatatcg- } \\
\text { gaacaa }\end{array}$ \\
\hline $\mathrm{Cdk} 2$ & CREB & 10 & 128142068 & 139 & No & $\begin{array}{l}\text { F: } 128142145 \text { 5'-ctatggaggtatagtcag- } \\
\text { gtat } \\
\text { R: } 128141946 \text { 5'-tctctgcctttctcagcctc }\end{array}$ \\
\hline CCND2 & CREB & 6 & 127101069 & 143 & Yes & $\begin{array}{l}\text { F: } 127101100 \text { 5'-gaggagatctaactgc- } \\
\text { ccttcc } \\
\text { R: } 127100957 \text { 5'-aagagtggaaggtgggc- } \\
\text { gagc }\end{array}$ \\
\hline CUL3 & CREB & 1 & 80337196 & 126 & Yes & $\begin{array}{l}\text { F:80337280 5'-tctgggccggatctcgtctc } \\
\text { R:80337154 5'-gctccctttatcgcgctcct }\end{array}$ \\
\hline
\end{tabular}

Table 1. Location of CREB binding sites in mouse gene and q-PCR primers for ChIP assays.

known to directly interact with AP1 protein ${ }^{43,44}$. The reporter assays demonstrated that AP1-mediated luciferase activity was reduced in mutant preadipocytes, consistent with reduced CCND2 mRNA due to the influence of THRA K283Q/K288R on AP1-mediated transcription.

Cullin 3 (Cul3) is the core component of cullin-RING-based BCR (BTB-Cul3-RBX1) E3 ubiquitin-protein ligase complex, which targets cyclin $\mathrm{E}$ for ubiquitin-directed degradation and controls S-entry ${ }^{45}$. The $\mathrm{S}$ entry delay and reduced Cul3 mRNA seen in human primary preadipocytes transfected with sumoylation-defective THRA K283Q/K288/R may be associated with altered CREB-mediated Cul3 gene transcription. We examined the CREB binding to CRE of the Cul3 gene. In wt-preadipocytes, the enrichment of CREB and THRA to the CRE was $4 \%$ and $12 \%$, respectively (Fig. 8 F). THRA enrichment was greater than CREB, suggesting that THRA may be able to bind in the vicinity of the CRE and facilitate Cul3 mRNA expression. In mutant-preadipocytes, the enrichment of THRA K283Q/K288R and CREB to the Cul3 gene was eliminated, resulting in a reduction in Cul3 mRNA by 36\% $(p<0.045)$ (Fig. 8G). The ChIP results indicate that in the presence of THRA K283Q/ K288R CREB-mediated gene expression of CCND1, Cdk2 and Cul3, was altered, consistent with the finding of delayed $\mathrm{G}_{1} / \mathrm{S}$ transition in THRA K283Q/K288R-transfected human preadipocytes.

THRA K2830/K288R is associated with reduced CREB binding to DNA and recruitment of NCoR. NCoR is a key regulator in THR-mediated transcription repression. NCoR protein contains two regions that specifically interact with unliganded $\mathrm{THR}^{46}$. Although THRA K283Q/K288R does not reduce T3 binding, as shown in a reporter assay, reduced sumoylation may alter the interface of THRA with other regulatory proteins. Using ChIP assays, we investigated whether an abnormal interaction between THRA K283Q/ K288R and NCoR alters CREB-mediated transcriptions in Wt-preadipocytes. At the CCND1-site1, neither THRA nor NCoR were enriched (Fig. 8H). At the CCND1-site2 (Fig. 8I), the enrichment of NCoR and THRA was detectable in very low levels in wt-preadipocytes, consistent with the lack of interaction between THRA and CREB on the CCND1 gene (Fig. 8C). In contrast, in mutant-preadipocytes, both THRA K283Q/K288R and NCoR were highly enriched and CREB reduced on the CCND1-site2.

Enrichment of THRA, but not NCoR, was observed at the Cdk2 CRE (Fig. 8J), indicating that THRA may interacts with CREB. At the Cul3 CRE, NCoR enrichment was not detectable in Wt-preadipocytes, although THRA enrichment was dominant (Fig. 8K). In mutant-preadipocytes, NCoR was enriched at the Cul3 CRE but not THRA K283Q/K288R, suggesting others factors contributing to NCoR enrichment. Concurrent recruitment of THRA K283Q/K288R and NCoR to CCND1 CRE-site 2 suggests that desumoylation of THRA alters THRA interaction with NCoR and CREB.

The ChIP data suggests that reduced THRA sumoylation may play a role in THRA interaction with other transcription factors, such as CREB and could impact the expression of CCND1, Cdk2 and Cul3 genes. Additionally, THRA sumoylation may be important for interaction with NCoR.

\section{Discussion}

TH is essential for cell proliferation during development and in regeneration after injury, as shown in a range of cellular and animal models ${ }^{2}$. TH regulates stem cell proliferation in the intestine, heart, brain, bone and skeletal muscle. In most tissues the stem cell proliferation is mediated by THRA, however, In the liver, regeneration of hepatic cells is regulated by THRB. THRA modulates the proliferation of the intestinal epithelial progenitors at the bottom of the crypts ${ }^{3,47,48}$. THRA/TH regulates cell growth and differentiation in the myocardium by 
stimulating specific genes and the AKT/mTOR pathway ${ }^{49-51}$. In the adult mouse brain, disruption of thyroid hormone signaling reduces neuroprogenitor survival, proliferation and differentiation ${ }^{52-54}$. In skeletal muscle THRA mediates myogenesis and tissue repair in response to injury ${ }^{55}$. THRA regulates bone growth and turnover via regulating differentiation of chondrocytes and osteoblasts and ossification ${ }^{56,57}$.

We used the THRA K283Q/K288R mouse model to investigate the impact of THRA sumoylation on adipocytes and fat deposition. In human primary preadipocytes, exogenous expression of mutant THRA (K283Q/ K283R), was associated with reduced nuclear protein content of cyclin D1, cyclin D2 and Cdk2 and downregulation of gene expression, leading to the delay of G1/S transition. In our mouse model, mutation at the THRASUMO conjugation site, K283Q/K288R, was associated with reduced WAT stores and reduced proliferation of preadipocytes as assessed by in vivo and in vitro labeling studies.

In general, an increased fraction of adipose stem cells, preadipocytes, is characteristic of metabolically healthy fat with the ability to expand fat storage by hyperplasia and reduce fat deposition in organs ${ }^{58}$. Adipocyte diameter varies by fat depot as well as differences in fat depot characteristics between genders. Expansion of fat stores by adipocyte hypertrophy and larger adipocytes diameter has been associated with insulin resistance and metabolic diseases. A number of studies, however, have associated smaller adipocyte diameter with insulin resistance and Type 2 diabetes ${ }^{59}$. A clinical study with $40 \%$ overfeeding for 8 weeks showed that those with smaller adipocyte diameter at baseline had a greater increase in insulin resistance that those with larger adipocytes ${ }^{60}$. Single cell expression profiling of adipose progenitors has shown at least three distinct populations of pre-adipocytes, further showing the complexity of assessing the role of preadipocytes in expansion of adipocyte stores ${ }^{61}$. Our mice with a THRA sumoylation site mutation showed a reduction in fat stores and serum leptin, although did not show significant adverse metabolic consequences of reduced preadipocytes. Addition of a high fat diet resulted in a greater difference between mutant and wt mice in the fraction of body fat and fat stores. Reduced fat stores may also be the result of enhanced energy expenditure. The impact of the desumoylated THRA on thermogenesis and metabolic rate will need to be directly evaluated.

The THRA sumoylation mutant was associated with reduced preadipocyte proliferation in the in vitro and in vivo model, so we investigated the pathways that may be involved. In the cell cycle G0/G1 transition, D-type cyclins D1 and D2 are rapidly synthesized to meet the cellular proliferation demand. cAMP response element binding protein (CREB), is an important regulator of the cell cycle through direct regulation of genes, including cyclin D1 (CCND1), cyclin D2 (CCND2) and cyclin-dependent kinase $2(C d k 2)^{19,22,27}$. THRs has been previously shown to antagonize CREB-mediated transcription by direct protein-protein interaction, independent of T3, as has been demonstrated previously in pituitary specific-Pit1 and interleukin (IL)-6 promoters ${ }^{37-39}$. A recent characterization of a desumoylated THRB showed a direct disruption of CREB-mediated gene transcription in the thyroid on genes important for thyroid hormone synthesis ${ }^{15}$. A functional screen of transcription response element promoters in our in vitro model, indicated reduced CREB signaling in the presence of desumoylated THRA.

SUMO conjugation alters receptor DNA-binding as well as interaction with binding partner and other transcription factors, altering gene expression and influencing cellular growth, proliferation and cellular function ${ }^{62}$. We utilized a ChIP assay to determine how the presence of the THRA sumoylation mutant influenced CREB signaling. The association of desumoylated THR with CREB inhibits CREB phosphorylation and ligand-dependent recruitment of coactivators, which impairs the CREB-mediated transcription and reduces cell proliferation ${ }^{37,38}$.

The role of THR/T3 in development has spatial and temporal specificity. THR may interact with various signals to facilitate the cellular demand in stem cells proliferation, although such activity does not occur in mature lineages. CCND1, CCND2 and Cdk2 mRNA level were reduced in G1 phase of mutant-preadipocytes. However, there was no change in mature adipocytes (WAT). The gene expression of D-type cyclins and Cdks are regulated by multiple transcription factors. For example, in addition to the two CREB binding sites, the CCND1 promoter region, within 200 bp of transcription starting site (TSS) also contains binding sites for AP1, Ets, SP1, Egr1, TCF, $\mathrm{NF}_{\mathrm{k}} \mathrm{B}$ and SATA $5^{63}$. These transcription factors may act in spatial and temporal manner. CREB is involved in G1 phase regulation.

The mutation in THRA sumoylation site was associated with alterations in CREB binding, with an observed reduction in gene expression. The THRA mutant mouse model permitted us to study the physiologic function of THRA-SUMO conjugation, without disrupting the DNA binding and T3-mediated signaling properties of THRA. In a previous report, a mutation in the second zinc finger of THRB disrupted THRB augmentation of PI3K signaling, independent of T3, but did not impair direct TH action or THR binding to DNA ${ }^{64}$. THR residues that do not mediate direct nuclear signaling are important for modulating cell signaling pathways. A number of factors, independent of T3, have been shown to regulate cytoplasmic and nuclear localization of THR, including posttranslational modification by acetylation ${ }^{65}$. This nuclear-cytoplasmic shuttling may be importat in cell cylce regulation. THRA sumoylation may play a role in preadipocyte proliferation though CREB-mediated gene expression of G1 regulators.

The mouse with a THRA gene mutation and reduced sumoylation had smaller fat pads and adipocyte diameter, as well as a marked reduction in serum leptin. These differences in fat deposition between mutant and wt mice was increased by placing mice on a high fat diet. Alterations in metabolic rate may contribute to the reduced fat stores. We measured a reduction of preadipocyte proliferation in vitro and in an in vivo model. We hypothesize that reduced THRA sumoylation disrupted CREB signaling and interfered with cell cycle regulation. Although the role of preadipocytes likely varies by fat depot, a reduced fraction of preadipocytes are characteristic of obese individuals and those with insulin resistance. THR sumoylation may play a role in the regulation of preadipocyte proliferation and maintainance of cardiometabolic health. 
Materials and methods

Animal use approval. Animal care and research protocol were approved by the institutional IACUC of VA Greater Los Angeles Healthcare System and in accordance with the Guide for the Care and Use of Laboratory Animals. All methods were carried out in accordance with ARRIVE Guidelines.

Generation of sumoylation defective THRA K2830/K288R mutant mice. The mutant mice were generated using FLP/FRT recombinase-mediated cassette exchange techniques (see Supplementary Fig. S1 online). The mutant mice were generated in C57BL/6NTac background. ES cells was derived from C57BL/ NTac mice and manipulated to create the desired targeted mutation in the mouse Thra gene. The ES cells with the Thra gene mutation were used as donors and injected to the acceptor embryos of the C57BL/6NTac mice. The embryos were implanted back to C57BL/NTac female mice. The pups, then, have the exact C57BL/6NTac genome except the specific Thra mutation. The mutation is located at exon 8 of THRA gene. The mutations are located at $1367 \mathrm{nt}$ (A to C) and $1381 \mathrm{nt}$ (A to G) based on NCBI accession \# NM_178060.4. The homozygous mutation was confirmed by direct DNA sequencing and High Resolution Melting curve. The homozygous mice were then bred to the same strain for at least three generations prior to using them in experiments. We used inhouse bred C57BL/6NTac mice with identical genetic background and living environment as the mutant mice for controls.

Animal care and experiments. Mice were maintained in a standard 12 - $\mathrm{h}$ light/12-h dark cycle with access to water and food ad libitum. Male mice were used in the study. Fasting serum T4, T3 and TSH and non-fasting serum leptin and adiponectin, were determined using Milliplex MAP magnetic Bead panel (Millipore Inc). Fasting serum cholesterol, free fatty acid and triglycerides levels were analyzed by Elisa Kit (Cayman Chemicals Inc). Fasting insulin using Elisa Kit from Crystal Chemical Inc.

Western blot detection and quantification of THRA and sumoylated THRA. Subcutaneous fat was dissected from Wt and THRA K283Q/K288R mice ( $\mathrm{n}=3$ /genotype). The tissues were rinsed in PBS and immediately lysed in RIPA buffer with complete protease inhibitors and SUMO peptidase inhibitor $20 \mu \mathrm{M}$ $\mathrm{N}$-ethylmaleimide (final concentration). After centrifugation at $12,000 \times \mathrm{g}$ for $10 \mathrm{~min}$ at $4{ }^{\circ} \mathrm{C}$, the clear supernatant (total lysate) was collected. Two 10\% SDS gels were prepared for western blots. Protein ( $35 \mu \mathrm{g} /$ lane) was loaded on the SDS gel. Upon completion of electrophoresis, the protein was transferred to PVDF membrane and Ponceau stained prior to blocking. The membrane \#1 was blotted with anti-THRA (1:500, Abcam Inc) and \#2 blotted with anti-SUMO2 (Developmental Studies Hybridoma Bank, 1:500). Membranes were imaged with Immobilon Forte Western HRP substrate (Millipore Inc). The western blots were quantified using Li-Cor Image Studio Lite. Western blot detected THRA and SUMO-THRA was normalized for total protein (Ponceau stained membrane) and presented as \% total protein.

Isolation and culture of mouse primary preadipocytes. Mouse primary preadipocytes were isolated from subcutaneous adipose tissue of wild type and THRA K283Q/K288R mutant mice using the method described previously ${ }^{66}$. In brief, 6 week-old male mice $(n=6)$ were euthanized. Subcutaneous fat pads were dissected, washed with PBS, and minced in $1 \mathrm{~mL}$ of advance DMEM/-F12 medium containing dipeptidase II (2.4 $\mathrm{U} / \mathrm{mL} / 10 \mathrm{mM} \mathrm{CaCl} 2)$ and collaginase $\mathrm{D}(1.5 \mathrm{U} / \mathrm{mL})$. After $1 \mathrm{~h}$ digestion at $37^{\circ} \mathrm{C}$ with agitation, the digestion was stopped by adding complete DMEM medium containing $10 \%$ FBS. After centrifuge for $10 \mathrm{~min}$ at $700 \times \mathrm{g}$, the pellet (stromal vascular fraction) was collected, resuspended in $1 \mathrm{~mL}$ PBS, and filtered through a $40 \mu \mathrm{M}$ cell strainer, and then plated to $1 \%$ collagen coated plates. After $1 \mathrm{~h}$ of plating, cells were carefully washed with warm PBS to remove unattached debris and fresh medium was added. The isolated cells were used immediately in subsequent experiments.

Chromatin immunoprecipitation (ChIP) assay. Preadipocytes isolated from inguinal fat were synchronized to $G_{1}$ phase as described the above. After the cells were re-fed with $10 \%$ calf serum for $8 \mathrm{~h}$, cells were fixed with formaldehyde (final concentration 1\%) for $10 \mathrm{~min}$. Fixation was then stopped with the addition of glycine. The remainder of the procedure followed the manufacturer's instructions for ChIP Kit (Qiagen Inc). For each ChIP reaction, 2 million cells were used. The antibodies used were anti-THRA (ab2743 ChIP grade, rabbit, Abcam Inc.), anti-NCoR (17-10260, ChIP grade, rabbit, Millipore Inc.), and anti-CREB (ab31387, ChIP grade, rabbit, Abcam Inc.). Normal rabbit IgG was used as negative control. The Input was 10\% pre-cleared total lysate. The purified DNA was PCR amplified for 35 cycles with triplicates. The data shown was deducted from negative control and expressed as \% Input enrichment. ChIP q-PCR primers were Qiagen pre-designed and are shown (Table 1).

In vivo EdU (5-ethynyl-2'-deoxyuridine) labeling of dividing preadipocytes in mice. EdU (Invitrogen) was prepared $50 \mu \mathrm{g} / \mathrm{mL}$ in saline and was administered to 3 week old mice $(\mathrm{n}=2)$ at $50 \mu \mathrm{g} / \mathrm{g} \mathrm{BW}$ (i.p.). Twelve hours after injection, mice were euthanized and inguinal fat was fixed in $4 \%$ paraformaldehyde in $4{ }^{\circ} \mathrm{C}$ overnight. The frozen tissue blocks were sectioned ( $12 \mu \mathrm{M}$ thickness). The EdU was detected by Click-IT chemistry following the manufacturer instructions (Thermofisher Scientific Inc.). The sections were then washed with PBS and blocked in blocking buffer (10\% goat serum and $0.03 \%$ tritonX-100 in PBS) for 30 min prior to incubation with anti- $\beta$-catenin antibody (Santa Cruz Biotech.) at dilution 1:25 overnight at $4{ }^{\circ} \mathrm{C}$, followed by goat-antirabbit Alexa Fluro 568 at dilution 1:2000 for $2 \mathrm{~h}$ at room temperature. The section was mounted with a coverslip using ProLong Gold anti-fade reagent containing DAPI for staining nucleus. The sections were searched at $\times 10$ 
magnification for vascular stromal areas and then these areas were examined in a $\times 20$ magnification field. EdUincoporated dividing cells were quantified by counting the green fluorescent labeled nucleus in three consecutive fields with 20X magnification in each mouse.

EdU labeling of proliferating preadipocytes cells isolated from mutant mice. Cells were isolated from the subcutaneous WAT of 6 week old wild type and mutant mice, grown to contact inhibition ( $48 \mathrm{~h}$ post $100 \%$ confluence), and then re-plated to 4 -chamber slides at $2 \times 10^{4}$ cells per chamber. EDU (Clik-it EDU kit) was added to culture medium at a final concentration of $10 \mu \mathrm{M}$ and incubated for $4 \mathrm{~h}$ in the culture incubator. Following fixation, cells were stained with Alexa Flour (594 or 488) for imaging. The number of EdU incorporated cells were quantified by counting total visible cells in a slide for 6 randomly selected frames and divided by the total visible DAPI labeled cells in these frames and presented as \% DAPI stained cells.

Cell diameter quantification. Mice ( $n=3$ /group) were fed with regular chow diet. The tissues were fixed by trans-cardial perfusion with $4 \%$ paraformaldehyde. Subcutaneous WAT was collected and paraffin embedded to prepare sections. The histology sections were imaged using Apical Imager. The cell diameter was quantified using ImageScope at similar location of inguinal fat pads of Wt and mutant mice. For each genotype, three sections were quantified at maximum enlargement for three consecutive frames. A total of 360 cells were measured for each genotype.

Quantification of total number of preadipocyte isolated from subcutaneous WAT of each mice. Preadipocytes were isolated from stromal vascular fraction (SVF) of subcutaneous fat of each mice $(n=3$ /genotype) as described above. Cells were collected and diluted in DMEM at low density. The number of preadipocytes were counted, using a hemocytometer, for 6 aliquots from each mouse.

Cell culture and transfections. Human primary preadipocytes from non-diabetic donors (Lonza Inc) were maintained in PBM-2 medium with 10\% FBS supplement (Lonza Inc). Cells were transfected with control plasmid (empty vector) and plasmids expressing hTHRA or hTHRA K283Q/K288R by electroporation, using a $4 \mathrm{D}$ Nucleofector device and primary cell-specific reagent (Lonza Inc).

$\mathrm{G}_{1}$ phase synchronization. Primary human preadipocytes (Lonza Inc) were grown to complete confluence and maintained for $48 \mathrm{~h}$ post-confluence. Cells were then trypsinized, washed twice with warm PBS and cultured in PBM-2 medium without serum for $48 \mathrm{~h}$. Primary preadiocytes isolated from the inguinal fat of Wt and THRA K283Q/K288R mutant mice were grown in DMEM with $10 \%$ calf serum to $80 \%$ confluence, then cultured for 3 days in DMEM with $0.5 \%$ calf serum before serum withdrawn. We observed that human primary preadipocytes tolerated $72 \mathrm{~h}$ of serum withdrawal without signs of apoptosis, but primary preadipocytes isolated from mice tolerated only $36 \mathrm{~h}$ of serum withdrawal. Preadipocytes from mice were, therefore, serum starved for $36 \mathrm{~h}$ to achieve $G_{1}$ synchronization. The number of cells synchronized to $G_{0} / G_{1}$ was measured by flow cytometry. To release cells to the cell cycle, $10 \%$ serum was supplied for the period $(0,8,16$ and $24 \mathrm{~h})$. Cells that underwent prolonged serum withdrawal required longer than the usual period in $\mathrm{G}_{1}$ phase to recover the cellular content and cellular activity before entering $S$ phase. For this reason, $G_{1} / S$ transition was analyzed $9 \mathrm{~h}$ after the cells were refed with serum.

Immunofluorescent (IF) staining and confocal imaging. Human primary preadipocytes were plated in chamber slides. Cell culture conditions, serum withdrawal and refeeding conditions, were the same as described for cell synchronization studies. Cells, $9 \mathrm{~h}$ after serum refeeding, were fixed with $4 \%$ paraformaldehyde, permeabilized in $0.2 \%$ TritonX-100/PBS, and then blocked with 5\% goat serum in PBS. Cells were incubated with primary antibodies at 1:100 concentration overnight and secondary antibodies at 1: 250 for $1 \mathrm{~h}$. Cells were then washed, mounted with Prolong Gold/DAPI (Life Science Inc.) and imaged using Zeiss Laser Scanning Microscope (LSM 710). The details on the antibodies details, see the section describing Western blot and IP/Co-IP procedures.

Cell cycle analysis by flow cytometry. Human primary preadipocytes were synchronized by serum withdrawal for $48 \mathrm{~h}$. Cells were collected at various time points $(0,8,16$ and $24 \mathrm{~h})$, after supplementation with $10 \%$ serum, and fixed for flow cytometry analysis with propidium iodine.

Quantitative RT-PCR analysis. Total RNA was isolated from cells (Qiagen kit). Primers used in q-PCR were pre-evaluated by Qiagen. The data were normalized with four housekeeping genes (GAPDH, beta-Actin, beta2-microglobulin and HPRT) and shown as the average of triplicate determinations.

RNA-seq analysis of gene expression. Total RNA was isolated from Inguinal fat of 3 month old male mice ( $n=3$ /genotype) and used in RNA-seq analysis. The library construction, RNA-seq and data analysis were performed by the Genomic Core Facility at UCLA.

Fractionation of nuclear and cytoplasmic proteins, immunoprecipitation (IP/co-IP) and Western Blot. Nuclear and cytoplasmic proteins were isolated using a Nuclear and Cytoplasmic Extraction Reagent (NE-PER) Kit (ThermoFisher Inc.) following the manufacturer's instructions. The fractioned components were used for IP/co-IP experiments. After IP/Co-IP, protein was separated by $10 \%$ SDS-PAGE, blotted to a PVC 
membrane, detected with antibodies, imaged, and quantified using Li-Cor Image Studio Lite. Antibodies used for IP/co-IP/WB were anti-cyclin D1 (sc-20044, mouse), anti-cyclin D2 (sc-181, rabbit), anti-CDK4 (sc-260, rabbit) and anti-Cdk2 (sc-163, rabbit), obtained from Santa Cruz Biotech Inc. Antibodies for p27kip (3686, rabbit), were from Cell Signaling Tech. All antibodies were used at 1:500 dilution for Western blot and 1:50 dilution for IP and co-IP experiments.

Luciferase reporter assay. Human primary preadipocytes were grown to contact inhibition, so cells would cease to proliferate. Cells were then trypsinized and transfected with Luciferase reporter using 4D Nucleofector device and plated to 96 -well dishes at $60 \%$ confluence, allowing cells to proliferate. Each Luciferase reporter (Qiagen Inc) contains six copies of a consensus response element for the transcription factors tested. Luciferase activity was determined $10 \mathrm{~h}$ after transfection using a Dual luciferase kit (Promega Inc.). The data are shown as the mean value of 6 replicates with standard deviation (SD).

Statistical analysis. PCR data was analyzed by 2-tailed student $t$-Test for paired comparison. For other experiments, One-way ANOVA or two-way ANOVA were used for statistical analysis. All data represent the mean value with standard deviation (SD). $P \leq 0.05$ was considered statistically significant.

\section{Data availability}

All data generated or analyzed during this study are included in this published article (and its Supplementary Information files). RNAseq data has been deposited in NCBI Gene Expression Omnibus (GEO) access GSE182723.

Received: 23 May 2021; Accepted: 1 December 2021

Published online: 16 December 2021

\section{References}

1. Brent, G. A. Mechanisms of thyroid hormone action. J. Clin. Invest. 122, 3035-3043. https://doi.org/10.1172/JCI60047 (2012).

2. Pascual, A. \& Aranda, A. Thyroid hormone receptors, cell growth and differentiation. Biochim. Biophys. Acta 1830, 3908-3916. https://doi.org/10.1016/j.bbagen.2012.03.012 (2013).

3. Kress, E., Samarut, J. \& Plateroti, M. Thyroid hormones and the control of cell proliferation or cell differentiation: Paradox or duality?. Mol. Cell Endocrinol. 313, 36-49. https://doi.org/10.1016/j.mce.2009.08.028 (2009).

4. White, U. \& Ravussin, E. Dynamics of adipose tissue turnover in human metabolic health and disease. Diabetologia 62, 17-23. https://doi.org/10.1007/s00125-018-4732-x (2019).

5. Tchoukalova, Y., Koutsari, C. \& Jensen, M. Committed subcutaneous preadipocytes are reduced in human obesity. Diabetologia 50, 151-157. https://doi.org/10.1007/s00125-006-0496-9 (2007).

6. Monteiro, R., Calhau, C. \& Azevedo, I. Comment on: Tchoukalova Y, Koutsari C, Jensen M (2007) Committed subcutaneous preadipocytes are reduced in human obesity. Diabetologia 50:151-157. Diabetologia 50, 1569. https://doi.org/10.1007/s00125007-0636-x (2007).

7. Bakker, A. H., Van Dielen, F. M., Greve, J. W., Adam, J. A. \& Buurman, W. A. Preadipocyte number in omental and subcutaneous adipose tissue of obese individuals. Obes. Res. 12, 488-498. https://doi.org/10.1038/oby.2004.55 (2004).

8. Mullur, R., Liu, Y. Y. \& Brent, G. A. Thyroid hormone regulation of metabolism. Physiol. Rev. 94, 355-382. https://doi.org/10.1152/ physrev.00030.2013 (2014).

9. Liu, Y. Y., Schultz, J. J. \& Brent, G. A. A thyroid hormone receptor alpha gene mutation (P398H) is associated with visceral adiposity and impaired catecholamine-stimulated lipolysis in mice. J. Biol. Chem. 278, 38913-38920. https://doi.org/10.1074/jbc.M3061 20200 (2003).

10. Liu, Y. Y. et al. A mutant thyroid hormone receptor alpha antagonizes peroxisome proliferator-activated receptor alpha signaling in vivo and impairs fatty acid oxidation. Endocrinology 148, 1206-1217. https://doi.org/10.1210/en.2006-0836 (2007).

11. Sjogren, M. et al. Hypermetabolism in mice caused by the central action of an unliganded thyroid hormone receptor alpha1. $E M B O$ J. 26, 4535-4545. https://doi.org/10.1038/sj.emboj.7601882 (2007).

12. Mishra, A., Zhu, X. G., Ge, K. \& Cheng, S. Y. Adipogenesis is differentially impaired by thyroid hormone receptor mutant isoforms. J. Mol. Endocrinol. 44, 247-255. https://doi.org/10.1677/JME-09-0137 (2010).

13. Liu, Y. Y., Kogai, T., Schultz, J. J., Mody, K. \& Brent, G. A. Thyroid hormone receptor isoform-specific modification by small ubiquitin-like modifier (SUMO) modulates thyroid hormone-dependent gene regulation. J. Biol. Chem. 287, 36499-36508. https:// doi.org/10.1074/jbc.M112.344317 (2012).

14. Liu, Y. Y. et al. Thyroid hormone receptor sumoylation is required for preadipocyte differentiation and proliferation. J. Biol. Chem. 290, 7402-7415. https://doi.org/10.1074/jbc.M114.600312 (2015).

15. Ke, S. et al. Thyroid hormone receptor beta sumoylation is required for thyrotropin regulation and thyroid hormone production. JCI Insight https://doi.org/10.1172/jci.insight.149425 (2021).

16. Davis, P. K., Ho, A. \& Dowdy, S. F. Biological methods for cell-cycle synchronization of mammalian cells. Biotechniques 30, 1322-1326, 1328, 1330-1321 (2001).

17. Coqueret, $\mathrm{O}$. New roles for p21 and p27 cell-cycle inhibitors: A function for each cell compartment?. Trends Cell Biol. 13, 65-70 (2003).

18. Desdouets, C. et al. Cell cycle regulation of cyclin A gene expression by the cyclic AMP-responsive transcription factors CREB and CREM. Mol. Cell Biol. 15, 3301-3309 (1995).

19. Persengiev, S. P. \& Green, M. R. The role of ATF/CREB family members in cell growth, survival and apoptosis. Apoptosis 8, 225-228 (2003).

20. Beier, F., Lee, R. J., Taylor, A. C., Pestell, R. G. \& LuValle, P. Identification of the cyclin D1 gene as a target of activating transcription factor 2 in chondrocytes. Proc. Natl. Acad. Sci. U S A 96, 1433-1438 (1999).

21. Watanabe, G. et al. Induction of cyclin D1 by simian virus 40 small tumor antigen. Proc. Natl. Acad. Sci. U S A 93, 12861-12866 (1996).

22. White, P. C. et al. Regulation of cyclin D2 and the cyclin D2 promoter by protein kinase A and CREB in lymphocytes. Oncogene 25, 2170-2180. https://doi.org/10.1038/sj.onc.1209255 (2006).

23. Brooks, A. R., Shiffman, D., Chan, C. S., Brooks, E. E. \& Milner, P. G. Functional analysis of the human cyclin D2 and cyclin D3 promoters. J. Biol. Chem. 271, 9090-9099 (1996).

24. Amati, B., Alevizopoulos, K. \& Vlach, J. Myc and the cell cycle. Front. Biosci. 3, d250-268 (1998). 
25. van Riggelen, J., Yetil, A. \& Felsher, D. W. MYC as a regulator of ribosome biogenesis and protein synthesis. Nat. Rev. Cancer 10, 301-309. https://doi.org/10.1038/nrc2819 (2010).

26. van Riggelen, J. \& Felsher, D. W. Myc and a Cdk2 senescence switch. Nat. Cell Biol. 12, 7-9. https://doi.org/10.1038/ncb0110-7 (2010).

27. Shiffman, D., Brooks, E. E., Brooks, A. R., Chan, C. S. \& Milner, P. G. Characterization of the human cyclin-dependent kinase 2 gene. Promoter analysis and gene structure. J. Biol. Chem. 271, 12199-12204 (1996).

28. Zalzali, H. et al. CDK2 transcriptional repression is an essential effector in p53-dependent cellular senescence-implications for therapeutic intervention. Mol. Cancer Res. 13, 29-40. https://doi.org/10.1158/1541-7786.MCR-14-0163 (2015).

29. Ho, K. K., Myatt, S. S. \& Lam, E. W. Many forks in the path: Cycling with FoxO. Oncogene 27, 2300-2311. https://doi.org/10.1038/ onc.2008.23 (2008).

30. Shaulian, E. \& Karin, M. AP-1 as a regulator of cell life and death. Nat. Cell Biol. 4, E131-136. https://doi.org/10.1038/ncb0502-e131 (2002).

31. Schorl, C. \& Sedivy, J. M. Loss of protooncogene c-Myc function impedes G1 phase progression both before and after the restriction point. Mol Biol Cell 14, 823-835. https://doi.org/10.1091/mbc.E02-10-0649 (2003).

32. Mayr, B. \& Montminy, M. Transcriptional regulation by the phosphorylation-dependent factor CREB. Nat. Rev. Mol. Cell Biol. 2, 599-609. https://doi.org/10.1038/35085068 (2001).

33. Grinstein, E., Jundt, F., Weinert, I., Wernet, P. \& Royer, H. D. Sp1 as G1 cell cycle phase specific transcription factor in epithelial cells. Oncogene 21, 1485-1492. https://doi.org/10.1038/sj.onc.1205211 (2002).

34. Schmidt, M. et al. Cell cycle inhibition by FoxO forkhead transcription factors involves downregulation of cyclin D. Mol. Cell Biol. 22, 7842-7852 (2002).

35. Matsuura, I. et al. Cyclin-dependent kinases regulate the antiproliferative function of Smads. Nature 430, 226-231. https://doi. org/10.1038/nature02650 (2004).

36. Attardi, L. D., de Vries, A. \& Jacks, T. Activation of the p53-dependent G1 checkpoint response in mouse embryo fibroblasts depends on the specific DNA damage inducer. Oncogene 23, 973-980. https://doi.org/10.1038/sj.onc.1207026 (2004).

37. Mendez-Pertuz, M., Sanchez-Pacheco, A. \& Aranda, A. The thyroid hormone receptor antagonizes CREB-mediated transcription. EMBO J. 22, 3102-3112. https://doi.org/10.1093/emboj/cdg295 (2003).

38. Fukuyama, K. et al. Thyroid hormone inhibits vascular remodeling through suppression of cAMP response element binding protein activity. Arterioscler. Thromb. Vasc. Biol. 26, 2049-2055. https://doi.org/10.1161/01.ATV.0000233358.87583.01 (2006).

39. De Luca, A. et al. p300/cAMP-response-element-binding-protein ('CREB')-binding protein (CBP) modulates co-operation between myocyte enhancer factor 2A (MEF2A) and thyroid hormone receptor-retinoid X receptor. Biochem. J. 369, 477-484. https://doi. org/10.1042/BJ20020057 (2003).

40. Furumoto, H. et al. An unliganded thyroid hormone beta receptor activates the cyclin D1/cyclin-dependent kinase/retinoblastoma/ E2F pathway and induces pituitary tumorigenesis. Mol. Cell Biol. 25, 124-135. https://doi.org/10.1128/MCB.25.1.124-135.2005 (2005).

41. Garcia-Silva, S. \& Aranda, A. The thyroid hormone receptor is a suppressor of ras-mediated transcription, proliferation, and transformation. Mol. Cell Biol. 24, 7514-7523. https://doi.org/10.1128/MCB.24.17.7514-7523.2004 (2004).

42. Herber, B., Truss, M., Beato, M. \& Muller, R. Inducible regulatory elements in the human cyclin D1 promoter. Oncogene 9 , 2105-2107 (1994).

43. Wondisford, F. E., Steinfelder, H. J., Nations, M. \& Radovick, S. AP-1 antagonizes thyroid hormone receptor action on the thyrotropin beta-subunit gene. J. Biol. Chem. 268, 2749-2754 (1993).

44. Lazar, M. A. Thyroid hormone action: A binding contract. J. Clin. Invest. 112, 497-499. https://doi.org/10.1172/JCI19479 (2003).

45. Singer, J. D., Gurian-West, M., Clurman, B. \& Roberts, J. M. Cullin-3 targets cyclin E for ubiquitination and controls S phase in mammalian cells. Genes Dev. 13, 2375-2387 (1999).

46. Astapova, I. et al. The nuclear corepressor, NCoR, regulates thyroid hormone action in vivo. Proc. Natl. Acad. Sci. U S A 105, 19544-19549. https://doi.org/10.1073/pnas.0804604105 (2008).

47. Plateroti, M., Kress, E., Mori, J. I. \& Samarut, J. Thyroid hormone receptor alpha1 directly controls transcription of the beta-catenin gene in intestinal epithelial cells. Mol. Cell Biol. 26, 3204-3214. https://doi.org/10.1128/MCB.26.8.3204-3214.2006 (2006).

48. Kress, E., Rezza, A., Nadjar, J., Samarut, J. \& Plateroti, M. The frizzled-related sFRP2 gene is a target of thyroid hormone receptor alpha1 and activates beta-catenin signaling in mouse intestine. J. Biol. Chem. 284, 1234-1241. https://doi.org/10.1074/jbc.M8065 48200 (2009).

49. Pantos, C. \& Mourouzis, I. Thyroid hormone receptor alphal as a novel therapeutic target for tissue repair. Ann. Transl. Med. 6, 254. https://doi.org/10.21037/atm.2018.06.12 (2018).

50. Pantos, C. et al. Thyroid hormone receptor alphal downregulation in postischemic heart failure progression: The potential role of tissue hypothyroidism. Horm. Metab. Res. 42, 718-724. https://doi.org/10.1055/s-0030-1255035 (2010).

51. Mourouzis, I., Forini, F., Pantos, C. \& Iervasi, G. Thyroid hormone and cardiac disease: From basic concepts to clinical application. J. Thyroid Res. 2011, 958626. https://doi.org/10.4061/2011/958626 (2011).

52. Desouza, L. A. et al. Thyroid hormone regulates hippocampal neurogenesis in the adult rat brain. Mol. Cell Neurosci. 29, 414-426. https://doi.org/10.1016/j.mcn.2005.03.010 (2005).

53. Kapoor, R. et al. Unliganded thyroid hormone receptor alphal impairs adult hippocampal neurogenesis. FASEB J. 24, 4793-4805. https://doi.org/10.1096/f.10-161802 (2010).

54. Lemkine, G. F. et al. Adult neural stem cell cycling in vivo requires thyroid hormone and its alpha receptor. FASEB J. 19, 863-865. https://doi.org/10.1096/fj.04-2916fje (2005).

55. Milanesi, A. et al. Thyroid hormone receptor alpha is essential to maintain the satellite cell niche during skeletal muscle injury and sarcopenia of aging. Thyroid 27, 1316-1322. https://doi.org/10.1089/thy.2017.0021 (2017).

56. Bassett, J. H. \& Williams, G. R. Role of thyroid hormones in skeletal development and bone maintenance. Endocr. Rev. 37, 135-187. https://doi.org/10.1210/er.2015-1106 (2016).

57. Desjardin, C. et al. Chondrocytes play a major role in the stimulation of bone growth by thyroid hormone. Endocrinology 155, 3123-3135. https://doi.org/10.1210/en.2014-1109 (2014).

58. Virtue, S. \& Vidal-Puig, A. Adipose tissue expandability, lipotoxicity and the Metabolic Syndrome: An allostatic perspective. Biochim. Biophys. Acta 1801, 338-349. https://doi.org/10.1016/j.bbalip.2009.12.006 (2010).

59. McLaughlin, T. et al. Enhanced proportion of small adipose cells in insulin-resistant vs insulin-sensitive obese individuals implicates impaired adipogenesis. Diabetologia 50, 1707-1715. https://doi.org/10.1007/s00125-007-0708-y (2007).

60. Johannsen, D. L. et al. Effect of 8 weeks of overfeeding on ectopic fat deposition and insulin sensitivity: Testing the "adipose tissue expandability" hypothesis. Diabetes Care 37, 2789-2797. https://doi.org/10.2337/dc14-0761 (2014).

61. Cho, D. S., Lee, B. \& Doles, J. D. Refining the adipose progenitor cell landscape in healthy and obese visceral adipose tissue using single-cell gene expression profiling. Life Sci. Alliance https://doi.org/10.26508/lsa.201900561 (2019).

62. Schimmel, J. et al. Uncovering SUMOylation dynamics during cell-cycle progression reveals FoxM1 as a key mitotic SUMO target protein. Mol. Cell 53, 1053-1066. https://doi.org/10.1016/j.molcel.2014.02.001 (2014).

63. Klein, E. A. \& Assoian, R. K. Transcriptional regulation of the cyclin D1 gene at a glance. J. Cell Sci. 121, 3853-3857. https://doi. org/10.1242/jcs.039131 (2008). 
64. Martin, N. P. et al. A rapid cytoplasmic mechanism for PI3 kinase regulation by the nuclear thyroid hormone receptor, TRbeta, and genetic evidence for its role in the maturation of mouse hippocampal synapses in vivo. Endocrinology 155, 3713-3724. https:// doi.org/10.1210/en.2013-2058 (2014).

65. Zhang, J., Roggero, V. R. \& Allison, L. A. Nuclear import and export of the thyroid hormone receptor. Vitam. Horm. 106, 45-66. https://doi.org/10.1016/bs.vh.2017.04.002 (2018).

66. Aune, U. L., Ruiz, L. \& Kajimura, S. Isolation and differentiation of stromal vascular cells to beige/brite cells. J. Vis. Exp. https:// doi.org/10.3791/50191 (2013).

\section{Acknowledgements}

This work was supported by NIH Grant (DK98576) and United States Veteran Administration Merit Review Grant (01BX001966), both to GAB.

\section{Author contributions}

Y.Y.L. and G.A.B. developed concept, designed studies, analyzed results and co-wrote the manuscript. Y.Y.L. also performed ChIP assays. J.J., S.K. and K.A. performed animal experiments, flow cytometry, ChIP and IP, G.G. performed tissue dissections, A.M. and J.L. performed EdU labeling and q-PCR.

\section{Competing interests}

The authors declare no competing interests.

\section{Additional information}

Supplementary Information The online version contains supplementary material available at https://doi.org/ 10.1038/s41598-021-03491-6.

Correspondence and requests for materials should be addressed to Y.-Y.L. or G.A.B.

Reprints and permissions information is available at www.nature.com/reprints.

Publisher's note Springer Nature remains neutral with regard to jurisdictional claims in published maps and institutional affiliations.

(c) (i) Open Access This article is licensed under a Creative Commons Attribution 4.0 International cc) License, which permits use, sharing, adaptation, distribution and reproduction in any medium or format, as long as you give appropriate credit to the original author(s) and the source, provide a link to the Creative Commons licence, and indicate if changes were made. The images or other third party material in this article are included in the article's Creative Commons licence, unless indicated otherwise in a credit line to the material. If material is not included in the article's Creative Commons licence and your intended use is not permitted by statutory regulation or exceeds the permitted use, you will need to obtain permission directly from the copyright holder. To view a copy of this licence, visit http://creativecommons.org/licenses/by/4.0/.

This is a U.S. Government work and not under copyright protection in the US; foreign copyright protection may apply 2021 